\title{
Phenotyping Chronic Musculoskeletal Pain in Male and Female Adolescents: Psychosocial Profiles, Somatosensory Profiles and Pain Modulatory Profiles
}

\author{
Don Daniel Ocay $\mathbb{D}^{1,2}$, Cynthia L Larche ${ }^{2}$, Natalie Betinjane ${ }^{2}$, Alexandre Jolicoeur ${ }^{2}$, \\ Marie Josee Beaulieu (D) ${ }^{2}$, Neil Saran ${ }^{3}$, Jean A Ouellet ${ }^{3}$, Pablo M Ingelmo (D) ${ }^{4-7}$, \\ Catherine E Ferland ${ }^{1,2,5-7}$
}

'Department of Experimental Surgery, McGill University, Montreal, QC, Canada; ${ }^{2}$ Department of Clinical Research, Shriners Hospitals for Children Canada, Montreal, QC, Canada; ${ }^{3}$ Department of Pediatric Orthopedics, McGill University, Montreal, QC, Canada; ${ }^{4}$ Edwards Family Interdisciplinary Center for Complex Pain, Montreal Children's Hospital, Montreal, QC, Canada; ${ }^{5}$ Department of Anesthesia, McGill University, Montreal, QC, Canada; ${ }^{6}$ Research Institute-McGill University Health Centre, Montreal, QC, Canada; ${ }^{7}$ Alan Edwards Research Center for Pain, McGill University, Montreal, QC, Canada

Correspondence: Catherine E Ferland, Shriners Hospitals for Children-Canada, I003, Decarie Blvd, Montreal, H4A 0A9, Canada, Tel +I 5I4 842-4464, extension 7177, Fax + 514 842-8664, Email catherine.ferland@mcgill.ca

Purpose: A major limitation in treatment outcomes for chronic pain is the heterogeneity of the population. Therefore, a personalized approach to the assessment and treatment of children and adolescents with chronic pain conditions is needed. The objective of the study was to subgroup pediatric patients with chronic MSK pain that will be phenotypically different from each other based on their psychosocial profile, somatosensory function, and pain modulation.

Patients and Methods: This observational cohort study recruited 302 adolescents (10-18 years) with chronic musculoskeletal pain and 80 age-matched controls. After validated self-report questionnaires on psychosocial factors were completed, quantitative sensory tests (QST) and conditioned pain modulation (CPM) were performed.

Results: Three psychosocial subgroups were identified: adaptive pain $(n=125)$, high pain dysfunctional $(n=115)$, high somatic symptoms ( $\mathrm{n}=62)$. Based on QST, four somatosensory profiles were observed: normal QST ( $\mathrm{n}=155)$, thermal hyperalgesia ( $\mathrm{n}=98)$, mechanical hyperalgesia $(n=34)$ and sensory loss $(n=15)$. Based on CPM and temporal summation of pain (TSP), four distinct groups were formed, dysfunctional central processing group $(n=27)$ had suboptimal CPM and present TSP, dysfunctional inhibition group $(n=136)$ had suboptimal CPM and absent TSP, facilitation group $(n=18)$ had optimal CPM and present TSP, and functional central processing $(\mathrm{n}=112)$ had optimal CPM and absent TSP. A significant association between the psychosocial and somatosensory profiles. However, no association was observed between the psychosocial or somatosensory profiles and pain modulatory profiles.

Conclusion: Our results provide evidence that adolescents with chronic musculoskeletal pain are a heterogenous population comprising subgroups that may reflect distinct mechanisms and may benefit from different treatment approaches. The combination of screening self-reported questionnaires, QST, and CPM facilitate subgrouping of adolescents with chronic MSK pain in the clinical context and may ultimately contribute to personalized therapy.

Keywords: adolescents, chronic pain, musculoskeletal pain, quantitative sensory testing, conditioned pain modulation, temporal summation of pain

\section{Introduction}

Chronic pain is common affecting $11-38 \%$ of the children and adolescents with musculoskeletal pain being one of the most common types of pain. ${ }^{1,2}$ Pain may have an idiopathic origin, may arise from a disease process, from treatments such as surgery, from trauma or injury, and may even involve pathological changes in central pain processing. ${ }^{3}$ Patients 
with chronic pain also may experience functional disability, higher rates of missed school, poor sleep quality and mental health problems. ${ }^{4-6}$ Understanding chronic pain in children and adolescents is crucial because about $20 \%$ of the children and adolescents living with chronic pain, have persistent pain in adulthood. ${ }^{7-10}$

A major limitation in treatment outcomes for chronic pain is the heterogeneity of the population. Moreover, there is lack of strong evidence on the efficacy or risk supporting the use pharmacological treatments in pediatric chronic pain. ${ }^{11}$ Therefore, a personalized approach to the assessment and treatment of children and adolescents with chronic pain conditions is needed. Researchers and clinicians have turned to identify heterogeneous subgroups of pediatric chronic pain patients. ${ }^{12-15}$ However, these studies strictly investigated pain and psychosocial characteristics in their cluster analysis. Moreover, there are limited data evaluating subgroups based on the changes in somatosensory function and pain modulation of pediatric patients with chronic pain conditions. ${ }^{16}$ Detailed phenotyping using recommended core outcomes, ${ }^{17}$ and tests such as quantitative sensory testing (QST) and conditioned pain modulation (CPM) may provide valuable information for individualized therapy.

The biopsychosocial approach to pain recognizes pain as a complex multidimensional experience that is the result of the interaction of biological, psychological and social factors. Each individual applies the term "pain" to a specific experience usually related to injury in their life, leading to different perception and expectation of pain. ${ }^{18}$ Therefore, recommended core outcomes for pain trials encompass measures of psychosocial factors (eg, pain catastrophizing, anxiety, depression, etc), pain variability and pain qualities, and sleep and fatigue. ${ }^{19}$ These domains can be assessed through standardized interviews or a diversity of self-reported questionnaires. Pain can be clinically divided into three categories reflecting an individual's somatosensory functioning: nociceptive, neuropathic and nociplastic. ${ }^{20}$ Many sophisticated quantitative sensory tests provide information on the nociceptive transduction and/or modulation from all aspects of the somatosensory system, leading to mechanism-based pain management. QST is a set of non-invasive tests that examines the somatosensory function in children and adolescents. ${ }^{21-23}$ Studies using static QST (ie, focusing on the determination of sensory threshold, or the rating of a single stimulus, and the corresponding magnitude of pain) have highlighted that in response to an objective sensory stimulus, either thermal or mechanical, an individual's perception and expectation of pain can be measured in a semi-objective manner. ${ }^{21,24-28}$ Studies in the pediatric population using dynamic QST (ie, focusing on the evaluation of pain modulation) have shown that chronic pain conditions are associated with altered excitatory and inhibitory endogenous pain modulation systems. ${ }^{10,15,29-36}$ The endogenous inhibitory pathways of pain modulation can be indirectly assessed using the CPM paradigm. ${ }^{29,37}$ Assessing CPM in a clinical setting may be a valuable tool to assess any deficits in the descending inhibitory pain response found in some chronic pain conditions such as abdominal pain and chronic musculoskeletal pain in youth when compared to healthy controls. $^{10,30,33,38,39}$ The endogenous facilitatory phenomenon of pain modulation such as temporal summation has been shown to be involved in the development of some chronic pain conditions such as sickle cell disease, fibromyalgia, migraines, and functional abdominal pain. ${ }^{15,34-36,40,41}$ Evaluating temporal summation through repeated or continuous painful stimulation, at a constant intensity, may help understand the mechanisms of central sensitization in children and adolescents and its role in the genesis and maintenance of some chronic pain conditions. ${ }^{15,34-36,40,41}$

The objective of the study was to subgroup pediatric patients with chronic MSK pain that will be phenotypically different from each other based on their psychosocial profile, somatosensory function, and pain modulation. We hypothesized that, through patient-reported outcomes extracted from questionnaires, and static and dynamic QST, distinct psychosocial profiles, somatosensory phenotypes and pain modulatory phenotypes would be identified in adolescents with chronic MSK pain.

\section{Materials and Methods}

Ethics approval was obtained prior to the beginning of the recruitment from the Research Ethics Board of McGill University (A09-M17-17B). The study was conducted in accordance with the Declaration of Helsinki. Participants received a written informed consent prior to inclusion in the study, and a signature was obtained by the participant (14 years old and older) or their parent/legal guardian prior to the beginning of the study (13 years old and younger). Reporting is in accordance with the STROBE (Strengthening the Reporting of Observational studies in Epidemiology) guidelines for cohort studies. ${ }^{42}$ Throughout the article, we use the World Health Organization definition of adolescents (persons aged between 10 and 19 years). ${ }^{43}$ 


\section{Participants}

Participant recruitment occurred between January 2018 and June 2021. Potential patients between 10 and 18 years old were identified by a research assistant at the orthopedic outpatient clinics of the Shriner's Hospital Canada and from the Edwards Family Interdisciplinary Center for Complex Pain of the Montreal Children's Hospital. Potential candidates for the study included patients reporting chronic primary or secondary musculoskeletal pain (persistent or recurrent pain at least once a week for longer than 3 months $)^{44}$ in their electronic medical charts or by reference of the patient's physician. At their hospital visit for treatment seeking either for an orthopedic condition or for pain itself, patients were approached by a research assistant to participate in the study and to confirm eligibility prior to receiving signed consent. Potential aged-matched controls between 10 and 18 years old were recruited through word of mouth, recruitment advertisements in local magazines and social media, and a collaborative high school near our institutions. As recommended, ${ }^{45}$ a screening checklist for control recruitment was completed by a research assistant to ensure eligibility of "healthy" participants. The exclusion criteria for age matched controls included 1) pain in the last 14 days, 2) pain lasting more than 24 hours on more than 3 days in the past 3 months, 3) taking more than 10 tablets of medication per month in the last 3 months, 4) suffering from diseases accompanied by long-lasting pain for longer than 3 months, 5) had psychological or psychiatric treatment for a long period in the past 5 years, 6) smoking more than 39 cigarettes per day, 7) drinking a lot of alcohol regularly, 8) consuming illegal drugs, including cannabis in the past month, 9) taking psychostimulants or other medication for therapeutic purposes regularly, and 10) having health issues, disorders or chronic dermal diseases in the tested areas. ${ }^{45}$ Participants who did not speak English or French or had a diagnosis of developmental delay that would interfere with completing measures were also excluded.

\section{Participant-Reported Outcome Measures \\ Sociodemographic Characteristics and Medical History}

Participant characteristics such as age, self-reported gender, ethnicity, past hospitalizations, and past surgeries were collected by a research assistant through face-to-face interviews.

\section{Pain Assessment}

Pain assessment was mainly conducted in the form of a face-to-face interview and with the use of standardized painrelated questionnaires that have been validated in clinical pediatric studies assessing pain. ${ }^{46-49}$ Patients were asked about the location of their primary site of pain using a body chart from the Adolescent Pediatric Pain Tool (APPT) ${ }^{50}$ which was divided into 67 sections, and the duration and frequency of their pain. The current pain intensity and average, worst and best pain intensity over the last month was reported using the numerical rating scale (NRS) ranging from 0 (no pain at all) to 10 (worst pain imaginable). Moreover, the pain experience was assessed using a list of 67 descriptive words in the APPT, assessing the four dimensions of pain (37 sensory, 11 affective, 8 evaluative and 11 temporal descriptive words). ${ }^{50}$ The APPT has been shown to have adequate content, construct, and criterion validity, and reliability in clinical and nonclinical groups of children and adolescents between 8 and 17 years old. ${ }^{51}$ To identify if their pain had a neuropathic component, the Douleur Neuropathique 4 (DN4) questionnaire was completed by patients and the physicians. By summing all 10 questions, scores of equal to or greater than 4 indicated that the pain experienced by the patient is likely neuropathic. ${ }^{46,52}$ The DN4 questionnaire has not been validated in children and adolescents. However, despite its very low-level evidence for satisfactory criterion validity and low-level evidence for satisfactory construct validity and reliability, the DN4 questionnaire has been described to be the most suitable for clinical use. ${ }^{53,54}$ The Functional Disability Inventory (FDI) questionnaire was completed by patients, in which the total score is summed to detect different levels of disability. ${ }^{55}$ The FDI has been reported to have high internal consistency, moderate-to-high test-retest reliability, moderate cross-informant (parent-child) reliability, and good predictive validity. ${ }^{48,55}$ The FDI is 15 -item scale using a Likert-type rating scale, ranging from 0 (no trouble) to 4 (impossible) for a maximum score of 60 (0-12 no/ minimal, 13-20 mild, 21-29 moderate, and $\geq 30$ severe disability). 


\section{Pain Catastrophizing}

The Pain Catastrophizing Scale for Children (PCS-C) was completed by patients and controls to assess the degree to which they experienced negative thoughts or feelings while experiencing pain. ${ }^{56}$ The PCS-C is a 13 -item scale and can be divided into three subscales: rumination, magnification and helplessness. Responses for each statement are done using a Likert-type rating scale, ranging from 0 (not at all) to 4 (extremely) for a maximum score of 52 (0-14 low, 15-25 moderate and $\geq 26$ high catastrophizing). ${ }^{57}$ The PCS-C has been shown to have good internal consistency ${ }^{58}$ as well as sufficient test-retest stability, ${ }^{59}$ and good construct and predictive validity. ${ }^{56}$ The cut-offs have been established to identify significant differences in child functioning across catastrophizing levels in children and adolescents with chronic pain. $^{57}$

\section{Anxiety and Depressive Symptoms}

The Revised Child Anxiety and Depression Scale (RCADS) questionnaire was completed by patients and controls to assess children's self-report of depression and anxiety. ${ }^{60}$ Based on the participant's age and grade in school, their total scores are converted into a $T$-score ( $\leq 64$ below, 65-69 borderline, and $\geq 70$ above clinical threshold). The RCADS has been validated in clinical and nonclinical groups of children and adolescents in grades 3-12, and showed good internal consistency (Cronbach $\alpha=0.78-0.88$ ) and item set and factor definitions consistent with DSM-IV anxiety disorders and depression. ${ }^{60,61}$

\section{Sleep Quality}

The Pittsburgh Sleep Quality Index (PSQI) questionnaire was completed by patients and controls to assess sleep quality, in which a global score of 5 or higher indicated poor sleep quality. ${ }^{62}$ The PSQI is the most commonly used measure in clinical and research settings showing good internal consistency (Cronbach $\alpha=0.70-0.83$ ) and has been validated in clinical and nonclinical groups of adolescents. ${ }^{63-65}$

\section{Quantitative Sensory Testing}

Each participant underwent a specific protocol of mechanical and thermal QST, lasting 37.0 \pm 11.5 minutes in a 22.7 \pm 0.7 ${ }^{\circ} \mathrm{C}$ private room, to obtain a comprehensive profile of somatosensory functioning adapted from previous studies to reduce complexity and time, and fit within the time constraints of clinical routines. ${ }^{28,66,67}$ For patient participants, mechanical QST was performed on the left volar forearm as the control area and followed by their most painful anatomical region indicated by the patient as the affected area. For "healthy" participants, mechanical QST was performed on the left volar forearm. For all participants, thermal QST was performed on the left volar forearm. Eight sensory parameters were tested in the same sequence and included:

1. Mechanical detection threshold (MDT). Calibrated von Frey filaments ranging between 0.008 and 300 grams were applied sequentially in an up-down method, and the threshold was measured as the geometrical mean of the three last detected and three first detected filaments.

2. Dynamic mechanical allodynia (DMA). A standardized brush exerting light touch at a single stroke for $2 \mathrm{~cm}$ in length was applied five times. The pain intensity (NRS 0-10) was reported after each stroke, and the average was calculated.

3. Vibration detection threshold (VDT). A tuning fork was applied to a joint or bony prominence of the tested area three times, and the threshold was measured as the average score at which the participants no longer detected the vibration $(\mathrm{x} / 8)$.

4. Mechanical pain summation (MPS). One and 10 stimulations from a calibrated pinprick were applied, and the participants reported their pain immediately at the end of the stimulation(s) and every 15 seconds post-stimuli during a 60 -second period. The whole sequence was conducted three times. The wind-up ratio (WUR) was measured as the ratio of the average pain intensity immediately reported after the train of 10 stimuli over the average pain intensity immediately reported after one stimulus. The presence of painful after-sensations (ie, pain intensity $>0$ using the NRS $0-10$ ) at the end of the 60 -second period after 1 and 10 stimuli were also noted. 
5. Pressure pain threshold (PPT). A handheld algometer was applied perpendicular to the body surface under underlying bone or muscle, and the threshold was measured as the mean of three trials.

6. Warm detection threshold (WDT), and heat pain threshold (HPT). A 9- $\mathrm{cm}^{2}$ warm calibrated thermode connected to a Q-sense apparatus (Medoc, Israel) with a baseline $32^{\circ} \mathrm{C}, 0.3^{\circ} \mathrm{C} /$ second upslope, and a limit of $50^{\circ} \mathrm{C}$ was applied three times. The thresholds were calculated from the mean of the 3 three trials for each modality (when they first sensed heat, and when they first reported pain).

\section{Conditioned Pain Modulation}

CPM assessment, lasting 22.3 \pm 4.1 minutes, was conducted using tonic heat on the right forearm as the test stimulus and the cold pressor task on the left arm as the conditioning stimulus as previously described protocols. ${ }^{29,33,68-71}$ For the test stimulus, a thermode was applied to the right volar forearm to reach a predetermined test temperature to a pain intensity $50 / 100$ (T50). The maximum value of $46.9^{\circ} \mathrm{C}$ was used as a security cut-off. Once the target temperature was reached, it remained constant for 120 seconds. To avoid expectation effects, participants were told that the temperature of the thermode could increase, remain stable or decrease and that they would have to evaluate their pain with a computerized visual analogue scale (CoVAS) throughout the test. This scale ranged from 0 (no pain) to 100 (worst pain imaginable). At the end of the 120 seconds of the test-stimulus, the average pain intensity during the 120 seconds was calculated. A cold pressor task (CPT) was used as the conditioning stimulus involving the immersion of their left forearm in a bath filled with cold water $\left(12^{\circ} \mathrm{C}\right)$ for 120 seconds to trigger the descending inhibitory pain response. Every 15 seconds, the participants were asked to report their pain intensity using the NRS 0-10. The average pain intensity during the conditioning stimulus was then calculated. If a participant removed their arm before the end of the 120 seconds, an average pain intensity score of $10 / 10$ was given. In order to evaluate the endogenous inhibitory pathways of pain modulation, and here measured as the CPM efficiency, the CPT was immediately followed by a second tonic heat test stimulus. The same pre-determined test temperature for each participant was used for the second tonic heat test stimulus. In addition, the thermode was not placed on the exact same area in the right volar forearm to avoid peripheral sensitization. CPM efficiency was measured as the percentage difference in average pain intensity of the test stimuli reported with the CoVAS such that a negative value for CPM response represents pain reduction with a more efficient CPM response $\left[100 \% \times\left(\mathrm{CoVAS}_{\text {after }}-\mathrm{CoVAS}_{\text {before }}\right) / \mathrm{CoVAS}_{\text {before }}\right]^{72} \mathrm{~A} \mathrm{CPM}$ efficiency between $-100 \%$ and $-30 \%$ was considered as optimal, between $-30 \%$ and $-10 \%$, suboptimal, and between $-10 \%$ and $+100 \%$, inefficient. These cut-offs were determined based on a clinical important change in pain intensity measured on an 11-point numerical pain rating scale. A $10-30 \%$ reduction in pain was labeled to be a minimal improvement, while a $30 \%$ reduction in pain intensity was labelled to be a clinically important difference in pain intensity, and is approximately the mean value of inhibitory conditioned pain modulation observed in previous studies. ${ }^{33,69-71}$ Endogenous facilitatory pain mechanisms, and here measured as temporal summation of pain (TSP), was assessed as the absolute difference in pain intensity during the last 60 seconds of the first test-stimuli (temporal summation phase). ${ }^{69}$ Based on previous studies, an increase in pain intensity was determined to be minimally clinically significant if the change was equal or larger than $2 / 10$ during the test stimuli. $^{73,74}$

\section{Statistical Analysis}

Data were analyzed using R Studio and plotted using Prism Version 9. QST parameters were analyzed in accordance with previous studies in adolescents. ${ }^{16,28}$ Analyses were based on available data, with no imputation for missing data. Descriptive statistics are presented as mean and standard deviation, unless otherwise specified. Differences between patients and healthy controls were compared with the Student $t$-test. Differences within patients and controls in regards to age, gender and race for the psychosocial, QST and CPM assessment outcomes were compared with using a three-way analysis of variance (ANOVA). Comparisons with the affected area thresholds in patients were based on within-cohort control measures at the control area. This gives sensitive within-participant comparisons for clinical testing. Comparisons with the control area thresholds in patients were based on between-cohort control measures at the control area. To compare QST parameters independently of their physical dimension, $z$-scores were calculated (eg, $z$-score $=$ affected

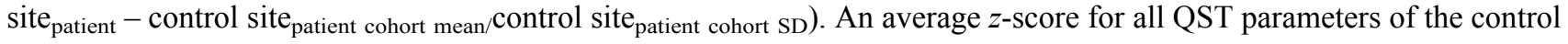


and affected area was then calculated for each patient. Gain of function (hyperalgesia) is indicated as a positive $z$-score and a loss of function (sensory loss) as a negative score.

Psychosocial profiles within the pediatric chronic pain sample were identified using an unsupervised clustering method performed using the FactoMineR package in the R Studio software. ${ }^{75}$ The cluster analysis involved nine quantitative indicator variables (pain catastrophizing, self-reported neuropathic component of pain, functional disability, sensory, affective, evaluative and temporal descriptors of pain, anxiety and depression symptoms, and sleep quality). Due to the different scales for each variable, the nine variables were standardized into $z$-scores to ensure that all variables are considered equally. Hierarchical clustering with k-means consolidation using the FactorMineR package in the R Studio software was conducted on the standardized indicator variables. The hierarchical clustering was therefore performed multiple times to minimize within-cluster variability and maximize between-cluster variability. The best partition of clusters was the one with the highest relative loss of inertia ${ }^{76}$ and based on parsimony. To determine cluster effect of the indicator variables, an ANOVA model was conducted along with a Scheffe test.

We used a deterministic approach to phenotype our patient cohort using the patient's somatosensory profile (sensory loss, mechanical hyperalgesia, thermal hyperalgesia or healthy). ${ }^{16,77,78}$ An ANOVA model was then conducted along with a Scheffe test to evaluate the main effect of the patients' somatosensory profiles using their QST values.

We used the pre-determined cut-offs mentioned above to subgroup our patient cohort based on their facilitatory and inhibitory pain modulation responses. ${ }^{79}$ Patients who displayed suboptimal or inefficient CPM and temporal summation of pain were included in the "dysfunctional central processing" subgroup. Patients who displayed optimal CPM and temporal summation of pain were grouped under the "facilitation" subgroup. Patients who displayed suboptimal or inefficient CPM and absence of temporal summation of pain were grouped under the "dysfunctional inhibition" subgroup. Patients who displayed optimal CPM and absence of temporal summation of pain were grouped under the "functional central processing" subgroup. An ANOVA model along with a Scheffe test was then conducted to evaluate the main effect of the CPM profiles of the patients on their CPM outcomes.

To investigate associations between psychosocial profiles, somatosensory profiles and pain modulatory profiles, a chisquare test was conducted. One-way ANOVAs were conducted for the distinct profiles to identify differences with regard to all outcome measures.

\section{Results}

\section{Patients Clinical Characteristics and Pain Assessment}

Three hundred and six patients with chronic musculoskeletal pain were recruited from January 2018 to June 2021 (Figure 1). Four patients were excluded after subsequent evaluation revealed they did not experience pain at least once a week $(n=3)$ or they had difficulty understanding and answering the interview questions $(n=1)$. Therefore, the data of 302 patients are presented (Table 1), but only 293 patients completed the CPM assessment (Figure 2). Eighty agematched controls were also recruited from January 2018 to June 2021. Age-matched controls were recruited through word of mouth ( $\mathrm{n}=22)$, our institution's staff children $(\mathrm{n}=16)$, our institution's patients relatives $(\mathrm{n}=6)$, pamphlets and social media $(\mathrm{n}=9)$, and a collaborative high school near our institution $(\mathrm{n}=27)$.

The primary location of pain of the patients included the head and neck $(n=11)$, upper limbs $(n=24)$, thorax $(n=4)$, back $(n=175)$, and lower limbs $(n=88)$. Pain radiated for $48 \%$ of the patients, and the presence of a secondary pain site was reported by $52 \%$ of the patients. Mild-moderate pain intensity ( $3.34 \pm 2.41)$ was reported by the patients the day of the assessment using the NRS $0-10$. Patients reported moderate intensity average pain (5.81 1.93$)$, severe intensity worst

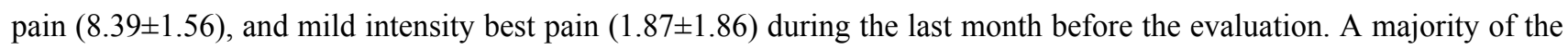
patients report their pain for more than 12 months ( $\mathrm{n}=223)$, while others report pain for 3-6 months $(\mathrm{n}=29)$ or between 6 and 12 months $(n=50)$. Most of the patients report pain at least once a day $(n=232)$, while 50 patients report pain every second day and 20 patients report pain only once a week. Moreover, most of the patients reported their painful episode to be constant $(n=180)$. Other durations of the painful episodes included a few seconds $(n=5)$, a few minutes $(\mathrm{n}=42)$ and a few hours $(\mathrm{n}=75)$. 


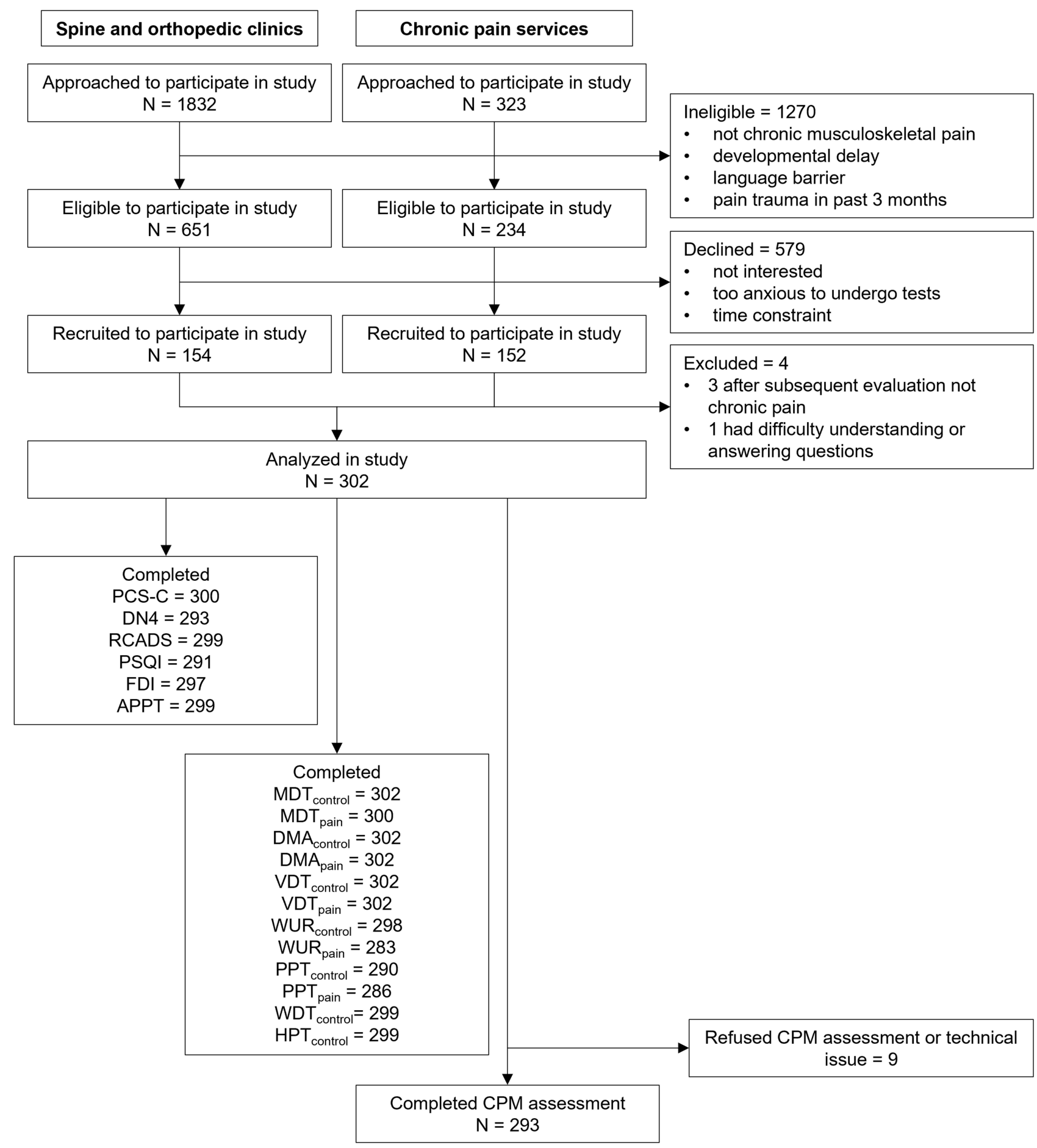

Figure I Flow chart of patient recruitment and evaluations.

Abbreviations: PCS-C, Pain Catastrophizing Scale - Child version; DN4, Douleur Neuropathique 4 questionnaire; RCADS, Revised Child Anxiety and Depression Scale; PSQI, Pittsburgh Sleep Quality Index; FDI, Functional Disability Inventory; APPT, Adolescent Pediatric Pain Tool; control, control area test site; pain, most painful location test site; MDT, mechanical detection threshold; DMA, dynamic mechanical allodynia; VDT, vibration detection threshold; WUR, wind-up ratio; PPT, pressure pain threshold; WDT, warm detection threshold; HPT, heat pain threshold; CPM, conditioned pain modulation.

\section{Differences Between Patients with Chronic Musculoskeletal Pain and Healthy Controls}

Patients reported significantly higher pain catastrophizing score, $T$-score for the RCADS, global score for the PSQI than controls (Table 1). Patients displayed a significantly lower vibration detection threshold and lower pressure pain 
Table I Characteristics of the Patient and Control Cohorts

\begin{tabular}{|c|c|c|c|c|c|}
\hline Variable & $\begin{array}{l}\text { Chronic MSK Pain } \\
\text { Patients }(n=302)\end{array}$ & $\begin{array}{c}\text { Age-Matched } \\
\text { Controls }(n=80)\end{array}$ & $\begin{array}{c}\text { Test } \\
\text { Statistic }\end{array}$ & p-value & $\begin{array}{c}\text { Cohen's } \\
\text { d }\end{array}$ \\
\hline $\begin{array}{l}\text { Age, mean } \pm \text { SD } \\
\text { Younger adolescent (10-13 years), n (\%) } \\
\text { Older adolescent ( } 14-18 \text { years), n (\%) }\end{array}$ & $\begin{array}{l}14.93 \pm 1.95 \\
87(28.81) \\
215(71.19)\end{array}$ & $\begin{array}{l}14.99 \pm 1.96 \\
20(25.00) \\
60(75.00)\end{array}$ & $\begin{array}{l}0.25 \dagger \\
0.29 *\end{array}$ & $\begin{array}{l}0.805 \\
0.593 \\
0.576\end{array}$ & \\
\hline $\begin{array}{l}\text { Gender, } \mathbf{n}(\%) \\
\text { Female } \\
\text { Male }\end{array}$ & $\begin{array}{c}247(81.79) \\
55(18.21)\end{array}$ & $\begin{array}{l}32(40.00) \\
48(60.00)\end{array}$ & $53.98 *$ & $<0.001$ & \\
\hline $\begin{array}{l}\text { Race }^{\mathbf{a}}, \mathbf{n}(\%) \\
\text { Caucasian (White) } \\
\text { Person of color }\end{array}$ & $\begin{array}{c}231(76.49) \\
70(23.18)\end{array}$ & $\begin{array}{l}58(72.50) \\
22(27.50)\end{array}$ & $0.4 I^{*}$ & 0.521 & \\
\hline $\begin{array}{l}\text { Past hospitalizations (>48 hours), } n \text { (\%) } \\
\text { No } \\
\text { Yes }\end{array}$ & $\begin{array}{l}212(70.20) \\
90(29.80)\end{array}$ & $\begin{array}{l}66(82.50) \\
14(17.50)\end{array}$ & $4.23 *$ & 0.040 & \\
\hline $\begin{array}{l}\text { Past surgeries, n (\%) } \\
\text { No } \\
\text { Yes }\end{array}$ & $\begin{array}{l}182(60.26) \\
120(39.74)\end{array}$ & $\begin{array}{l}55(68.75) \\
25(21.25)\end{array}$ & $1.59 *$ & 0.207 & \\
\hline $\begin{array}{l}\text { Adolescent Pediatric Pain Tool } \\
\text { Pain locations, } x / 67 \\
\text { Sensory descriptors, } x / 37 \% \\
\text { Affective descriptors, } x / 11 \% \\
\text { Evaluative descriptors, } x / 8 \% \\
\text { Temporal descriptors, } x / 24 \%\end{array}$ & $\begin{aligned} 8.78 & \pm 8.40 \\
23.26 & \pm 15.36 \\
15.57 & \pm 17.41 \\
43.73 & \pm 24.52 \\
29.01 & \pm 15.96\end{aligned}$ & $\begin{array}{l}- \\
- \\
- \\
-\end{array}$ & & & \\
\hline $\begin{array}{l}\text { Douleur Neuropatique } 4 \text { questionnaire } \\
\text { Total score, mean } \pm \text { SD } \\
\text { Likely neuropathic, n (\%) }\end{array}$ & $\begin{array}{l}2.96 \pm 2.03 \\
133(44.04)\end{array}$ & - & & & \\
\hline $\begin{array}{l}\text { Functional Disability Inventory } \\
\text { Total score } \\
\text { No/minimal disability, n (\%) } \\
\text { Mild disability, n (\%) } \\
\text { Moderate disability, n (\%) } \\
\text { Severe disability, n (\%) }\end{array}$ & $\begin{array}{l}15.79 \pm 9.76 \\
119(39.40) \\
80(26.49) \\
71(23.51) \\
27(8.94)\end{array}$ & $\begin{array}{l}- \\
- \\
- \\
-\end{array}$ & & & \\
\hline $\begin{array}{l}\text { Pain catastrophizing scale } \\
\text { Total score, mean } \pm \text { SD } \\
\text { Low catastrophizers, } n(\%) \\
\text { Moderate catastrophizers, } \mathrm{n}(\%) \\
\text { High catastrophizers, } \mathrm{n}(\%)\end{array}$ & $\begin{array}{l}28.40 \pm 9.98 \\
30(9.93) \\
84(27.81) \\
186(61.59)\end{array}$ & $\begin{array}{l}18.55 \pm 8.77 \\
29(36.25) \\
36(45.00) \\
15(18.75)\end{array}$ & $\begin{array}{c}8.66^{\dagger} \\
56.145^{*}\end{array}$ & $\begin{array}{l}<0.001 \\
<0.001\end{array}$ & 1.01 \\
\hline $\begin{array}{l}\text { Revised Child Anxiety and Depression Scale } \\
\text { Total T-score, mean } \pm \text { SD } \\
\text { Below clinical threshold, } \mathrm{n}(\%) \\
\text { Borderline clinical threshold, } \mathrm{n}(\%) \\
\text { Above clinical threshold, } \mathrm{n}(\%)\end{array}$ & $\begin{array}{c}52.27 \pm 14.08 \\
244(80.79) \\
10(3.31) \\
45(14.90)\end{array}$ & $\begin{array}{c}46.35 \pm 11.59 \\
74(92.50) \\
1(1.25) \\
5(6.25)\end{array}$ & $\begin{array}{l}3.87^{\dagger} \\
5.55^{*}\end{array}$ & $\begin{array}{c}<0.001 \\
0.062\end{array}$ & 0.44 \\
\hline $\begin{array}{l}\text { Pittsburgh Sleep Quality Index } \\
\text { Total score, mean } \pm \text { SD } \\
\text { Good sleep quality, n (\%) } \\
\text { Poor sleep quality, n (\%) }\end{array}$ & $\begin{array}{l}7.81 \pm 3.77 \\
62(20.53) \\
229(75.83)\end{array}$ & $\begin{array}{l}4.88 \pm 2.61 \\
35(43.75) \\
43(53.75)\end{array}$ & $\begin{array}{l}7.93^{\dagger} \\
16.43^{*}\end{array}$ & $\begin{array}{l}<0.001 \\
<0.001\end{array}$ & 0.82 \\
\hline
\end{tabular}

(Continued) 
Table I (Continued).

\begin{tabular}{|c|c|c|c|c|c|}
\hline Variable & $\begin{array}{l}\text { Chronic MSK Pain } \\
\text { Patients }(n=302)\end{array}$ & $\begin{array}{c}\text { Age-Matched } \\
\text { Controls }(n=80)\end{array}$ & $\begin{array}{c}\text { Test } \\
\text { Statistic }\end{array}$ & p-value & $\begin{array}{c}\text { Cohen's } \\
\text { d }\end{array}$ \\
\hline $\begin{array}{l}\mathbf{M D T}^{\mathbf{l o g}}(\mathbf{m N}), \text { mean } \pm \mathbf{S D} \\
\text { Control area } \\
\text { Tested area }\end{array}$ & $\begin{array}{l}0.69 \pm 1.22 \\
0.67 \pm 1.77\end{array}$ & $\begin{array}{c}0.42 \pm 1.05 \\
-\end{array}$ & $\begin{array}{l}1.93^{\dagger} \\
0.60^{\ddagger}\end{array}$ & $\begin{array}{l}0.055 \\
0.552\end{array}$ & \\
\hline $\begin{array}{l}\text { DMA }^{\log }(\mathbf{N R S} \mathbf{0}-\mathbf{1 0}) \text {, mean } \pm \text { SD } \\
\text { Control area } \\
\text { Tested area }\end{array}$ & $\begin{array}{l}-4.27 \pm 1.18 \\
-3.40 \pm 2.07\end{array}$ & $\begin{array}{c}-4.53 \pm 0.48 \\
-\end{array}$ & $\begin{array}{l}3.01^{\dagger} \\
7.74^{\ddagger}\end{array}$ & $\begin{array}{c}0.003 \\
<0.001\end{array}$ & $\begin{array}{l}0.24 \\
0.52\end{array}$ \\
\hline $\begin{array}{l}\text { VDT }(\mathbf{x} / \mathbf{8}), \text { mean } \pm \text { SD } \\
\text { Control area } \\
\text { Tested area }\end{array}$ & $\begin{array}{l}6.72 \pm 0.98 \\
5.96 \pm 1.35\end{array}$ & $\begin{array}{c}7.04 \pm 0.85 \\
-\end{array}$ & $\begin{array}{l}2.92^{\dagger} \\
17.18^{\ddagger}\end{array}$ & $\begin{array}{c}0.004 \\
<0.001\end{array}$ & $\begin{array}{l}0.34 \\
0.64\end{array}$ \\
\hline $\begin{array}{l}\text { WUR } \\
\text { Control area } \\
\text { Presence of painful after sensations after } 10 \text { stimuli } \\
\text { in the control area, } n(\%) \\
\text { Tested area } \\
\text { Presence of painful after sensations after } 10 \text { stimuli } \\
\text { in the tested area, } n(\%)\end{array}$ & $\begin{array}{l}0.75 \pm 0.98 \\
113(37.42) \\
0.66 \pm 1.03 \\
126(41.72)\end{array}$ & $\begin{array}{l}0.60 \pm 0.54 \\
17(21.25) \\
\\
17(21.25)\end{array}$ & $\begin{array}{l}1.81^{\dagger} \\
7.05^{*} \\
0.62^{\ddagger} \\
13.19^{*}\end{array}$ & $\begin{array}{c}0.072 \\
0.008 \\
0.534 \\
<0.001\end{array}$ & \\
\hline $\begin{array}{l}\mathbf{P P T}^{\mathbf{l o g}}(\mathbf{k P a}), \text { mean } \pm \mathbf{S D} \\
\text { Control area } \\
\text { Tested area }\end{array}$ & $\begin{array}{l}5.11 \pm 0.47 \\
5.11 \pm 0.65\end{array}$ & $\begin{array}{c}5.38 \pm 0.54 \\
-\end{array}$ & $\begin{array}{l}4.01^{\dagger} \\
2.26^{\ddagger}\end{array}$ & $\begin{array}{l}<0.001 \\
0.024\end{array}$ & $\begin{array}{l}0.55 \\
<0.01\end{array}$ \\
\hline $\begin{array}{l}\text { WDT }^{\text {log }}\left({ }^{\circ} \mathrm{C} \text { from baseline), mean } \pm \mathrm{SD}\right. \\
\text { Control area }\end{array}$ & $0.43 \pm 0.69$ & $0.48 \pm 0.66$ & $0.64^{\dagger}$ & 0.523 & \\
\hline $\begin{array}{l}\text { HPT }\left({ }^{\circ} \mathbf{C}\right) \text {, mean } \pm \text { SD } \\
\text { Control area }\end{array}$ & $39.35 \pm 2.73$ & $39.02 \pm 2.60$ & $0.99^{\dagger}$ & 0.324 & \\
\hline $\begin{array}{l}\text { CPM efficiency (\%), mean } \pm \text { SD } \\
\text { Inefficient, } n(\%) \\
\text { Suboptimal, } n(\%) \\
\text { Optimal, n (\%) }\end{array}$ & $\begin{array}{c}-22.16 \pm 44.28 \\
104(34.44) \\
60(19.87) \\
130(43.05)\end{array}$ & $\begin{array}{c}-33.37 \pm 33.28 \\
18(22.50) \\
16(20.00) \\
46(57.50)\end{array}$ & $\begin{array}{l}2.48^{\dagger} \\
5.56^{*}\end{array}$ & $\begin{array}{l}\mathbf{0 . 0 1 4} \\
0.062\end{array}$ & 0.27 \\
\hline $\begin{array}{l}\text { TSP (NRS }-10-+10) \text {, mean } \pm \text { SD } \\
\text { Absence, } n(\%) \\
\text { Presence, } n(\%)\end{array}$ & $\begin{array}{c}0.02 \pm 2.27 \\
249(82.45) \\
45(14.90)\end{array}$ & $\begin{array}{l}0.33 \pm 2.05 \\
66(82.50) \\
14(17.50)\end{array}$ & $\begin{array}{l}1.16^{\dagger} \\
0.09 *\end{array}$ & $\begin{array}{l}0.25 \\
0.76 I\end{array}$ & \\
\hline
\end{tabular}

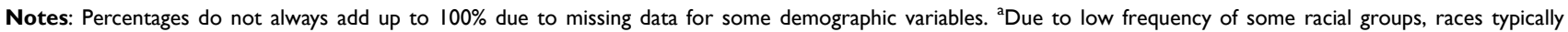
identified by Statistics Canada as a visible minority group (American Indian or Alaska Native, Asian, Black or African American, Latin American, Arab, and Mixed Race) were collapsed into a single category. ${ }^{*}$ Test statistic for chi-square test. ${ }^{\dagger}$ Test statistic for Student's $t$-test between patients and controls. ${ }^{*}$ Test statistic for Student's $t$-test between control area and tested pain area. Significant $p$-values $<0.05$ are bolded. Cohen's $d$ values are displayed for significant $p$-values for the Student's $t$-test $(0.2-$ small; $0.5-$ medium, 0.8 - large).

Abbreviations: MSK, musculoskeletal; log, log-transformed data; MDT, mechanical detection threshold; DMA, dynamic mechanical allodynia; VDT, vibration detection threshold; WUR, wind-up ratio; PPT, pressure pain threshold; WDT, warm detection threshold; HPT, heat pain threshold; CPM, conditioned pain modulation; TSP, temporal summation of pain.

threshold than controls (Table 1). Furthermore, patients displayed a significantly less efficient conditioned pain modulation than age-matched controls.

A significant main effect of age, gender and race was heterogeneously present across the psychosocial, QST and CPM assessment outcomes (for details see Supplementary Tables 1 and 2). However, subsequent post-hoc comparisons were not significant, except for younger adolescent (10-13 years) controls displaying a lower pressure pain threshold than the older (14-18 years) controls $(\mathrm{p}=0.003)$. 

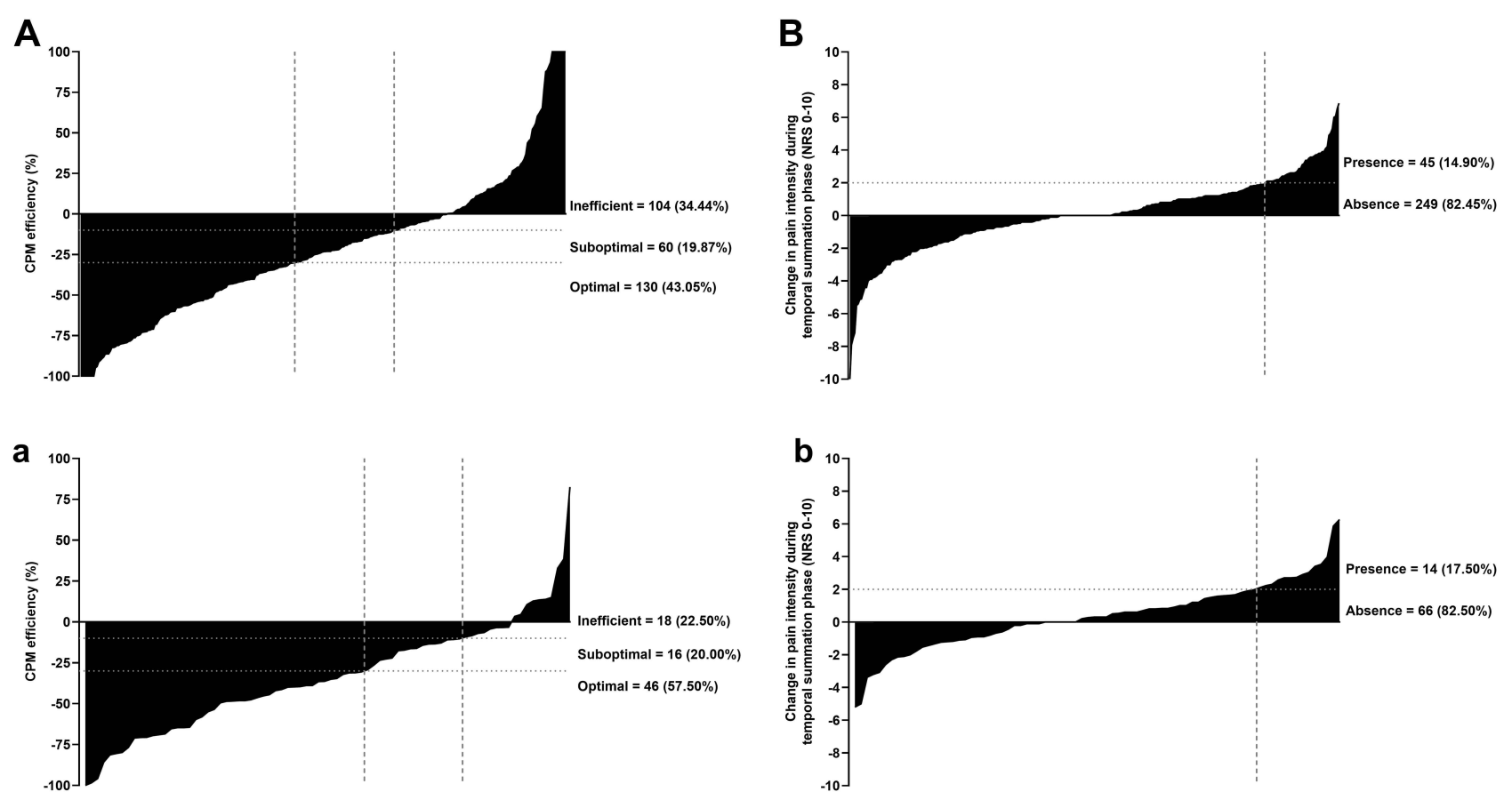

Figure 2 Inhibitory and facilitatory pain modulations responses in adolescents with chronic musculoskeletal pain and age-matched controls. The distribution of conditioned pain modulation in (A) patients and (a) age-matched controls show a spectrum of individual responses. Bar = individual participants. A CPM efficiency between - I00\% and $-30 \%$ was considered as optimal, between $-30 \%$ and $-10 \%$ suboptimal and between $-10 \%$ and $+100 \%$ inefficient. The distribution of temporal summation of pain during the test stimulus before the conditioning stimulus in (B) patients and (b) age-matched controls also show a spectrum of individual responses. Bar $=$ individual participants. An increase in pain intensity was determined minimum clinically significant if the change was equal or larger than 20/I00 during the last 60 seconds of the first test stimulus (ie, presence of temporal summation of pain).

\section{Self-Reported Questionnaires Identifies Distinct Psychosocial Profiles}

Based on the highest relative loss of inertia and parsimony, the best partition of psychosocial profiles of the chronic pain sample was three clusters accounting for $31.27 \%$ of the total variation in the data. Psychosocial profiles differed significantly from each other $\left(F_{2,2649}=622.00, \mathrm{p}<0.001\right)$, and psychosocial parameter $\times$ profile interaction $\left(F_{16,2649}=\right.$ 13.87, $\mathrm{p}<0.001)$ was observed, meaning that a patient's response to a specific questionnaire differed based on their profile. No significant main effect of the psychosocial parameters was observed $\left(F_{8,2649}=1.03, \mathrm{p}=0.412\right)$ (Figure 3A).

Adaptive pain (AP) cluster: One hundred and twenty-five patients (41\%) were grouped in this cluster. Patients grouped in the AP cluster reported significantly the lowest scores for pain catastrophizing, were less likely to report their pain as neuropathic in nature, report less functional disability, less locations of pain, less descriptors of pain, reported less anxiety and depression symptoms and better sleep quality than the other two clusters (see Supplementary Table 3). Patients grouped in the AP cluster reported higher scores for pain catastrophizing, but similar scores for anxiety and depression symptoms and sleep quality than controls (Figure 3B-D).

High pain dysfunctional (HPD) cluster: one-hundred and fifteen (38\%) were grouped in this cluster. Patients in the HPD cluster 2 reported significantly higher scores for nearly all questionnaires than the AP cluster, except similar number of temporal descriptors of pain. Patients in the HPD cluster were significantly older compared to those in the AP cluster. Moreover, patients in the HPD cluster reported significantly higher pain intensity the day of the assessment, and higher average, worst and best pain intensity over the last month compared with patients in the AP cluster (see Supplementary Table 3). Patients grouped in the HPD cluster reported higher scores for pain catastrophizing, more anxiety and depression symptoms and worst sleep quality than controls (Figure 3B-D).

High somatic symptoms (HSS) cluster: Sixty-two patients (21\%) were grouped in this cluster. Patients in the HSS cluster reported similar scores for the Functional Disability Inventory, the Revised Child Anxiety and Depression Scale, and the Pittsburgh Sleep Quality Index, and reported a similar number of pain locations than those of the HPD cluster. 

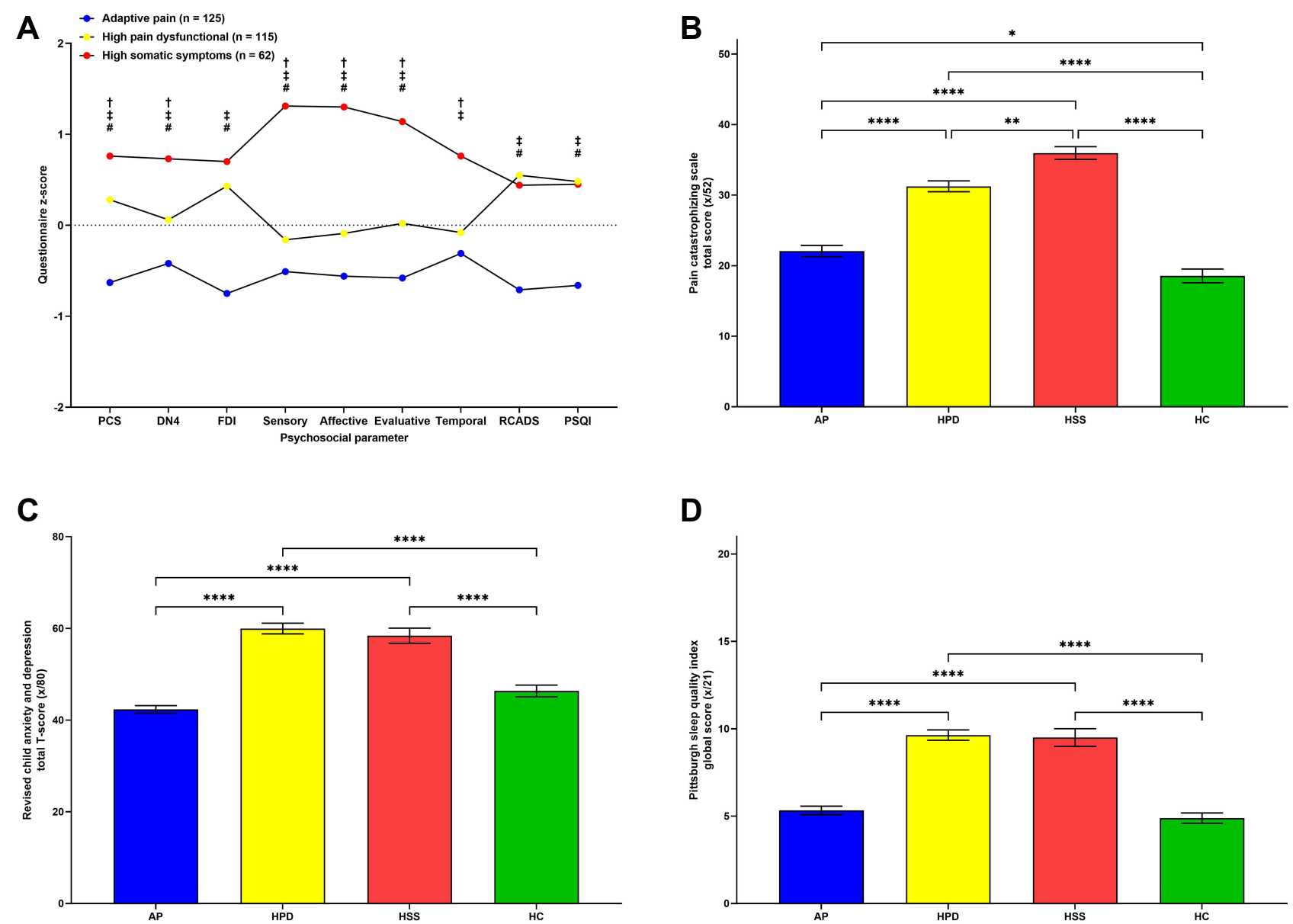

Figure 3 Psychosocial profiles in adolescents with chronic musculoskeletal pain. (A) Individual patient questionnaire scores were transformed and presented as z-scores. Higher z-scores represent higher scores for the questionnaire completed. Differences are significant if $p<0.05$ Significant difference between ${ }^{\#}$ the adaptive pain and high pain dysfunctional cluster, ${ }^{\ddagger}$ the adaptive pain and high somatic symptoms cluster or ${ }^{\dagger}$ the high pain dysfunctional and high somatic symptoms cluster. Data points $=$ mean. $(\mathbf{B})$ The pain catastrophizing score is represented by psychosocial cluster and compared with age-matched controls. Bars $=$ mean \pm SEM. $(\mathbf{C})$ The Revised Child Anxiety and Depression Scale total T-score is represented by psychosocial cluster and compared with age-matched controls. Bars $=$ mean \pm SEM. (D) The Pittsburgh Sleep Quality Index global score is represented by psychosocial cluster and compared with age-matched controls. Bars $=$ mean \pm SEM. ${ }^{*} \mathrm{p}<0.05$, $* * p<0.0 \mathrm{I},{ }^{* * * *} \mathrm{p}<0.000 \mathrm{I}$. PCS-C, pain Catastrophizing Scale - Child version; DN4, Douleur Neuropathique 4 questionnaire; FDI, Functional disability inventory; Sensory, sensory descriptors; Affective, affective descriptors; Evaluative, evaluative descriptors; Temporal, temporal descriptors; RCADS, Revised Child Anxiety and Depression Scale.

Abbreviations: PSQI, Pittsburgh Sleep Quality Index; AP, adaptive pain; HPD; high pain dysfunctional; HSS; high somatic symptoms; HC, healthy controls.

However, patients grouped in the HSS cluster reported significantly higher scores for the pain catastrophizing, were more likely to report their pain as neuropathic in nature, and use more descriptors of pain (sensory, affective, evaluative, and temporal) than the HPD cluster. Patients in the HSS cluster also reported higher pain intensity the day of the assessment, in higher average, worst and best pain intensity over the last month compared with patients in the AP cluster (see Supplementary Table 3). Patients grouped in the HSS cluster reported higher scores for pain catastrophizing, more anxiety and depression symptoms and worst sleep quality than controls (Figure 3B-D).

\section{Quantitative Sensory Testing Identifies Distinct Somatosensory Profiles}

For each adolescent patient, pain site $z$-scores were calculated using control measures for their forearm and for age-matched controls, and plotted across available modalities. A deterministic approach was taken for allocation to the closest matching profile including healthy controls. Profiles of sensory loss thermal hyperalgesia, mechanical hyperalgesia and normative QST differed significantly from each other, with a significant main effect of somatosensory profile $\left(F_{3,2043}=39.51, \mathrm{p}<0.001\right)$, modality $\left(F_{6,2043}=37.46, \mathrm{p}<0.001\right)$, and modality $\times$ somatosensory profile interaction $\left(F_{18,2043}=14.05, \mathrm{p}<0.001\right)$. Clinical characteristics and pain intensity did not vary across somatosensory profiles (see Supplementary Table 4 ). 
Out of the 302 patients, 155 (51\%) displayed normative QST values comparable to healthy controls. Thermal hyperalgesia was the most common profile in our cohort of adolescents with chronic MSK pain $(n=98 ; 32 \%)$. This included increased sensitivity to mechanical stimuli, WDT and HPT (Figure 4, for details, see Supplementary Table 4). Fifteen (5\%) patients presented sensory loss profile with decreased sensitivity to mechanical and thermal stimuli. Mechanical hyperalgesia was observed for 34 (11\%) patients with marked loss of function in HDT and HPT, and gain of function in PPT. Wind-up did not differentiate between somatosensory profiles.

\section{Conditioned Pain Modulation Assessment Identifies Distinct Profiles}

Four distinct pain modulatory profiles within patients were observed: patients with optimal CPM efficiency and absence of temporal summation (ie, functional central processing; $n=112$ ), patients displaying only temporal summation of pain (ie, facilitation; $\mathrm{n}=18$ ), patients displaying only suboptimal or inefficient CPM (ie, dysfunctional inhibition; $\mathrm{n}=136$ ), and patients displaying both suboptimal or inefficient CPM and presence of temporal summation of pain (ie, dysfunctional central processing; $n=27$ ) (Figure 5). Demographic characteristics and pain intensity did not vary across pain modulatory profiles (see Supplementary Table 5).

\section{Associations Between Psychosocial Profiles and Somatosensory Profiles and Pain Modulatory Profiles}

As factors have been shown to influence QST and CPM in adolescents, associations between the psychosocial profiles, somatosensory profiles and pain modulatory profiles were assessed (Figure 6). A chi-square test revealed a significant association between the psychosocial and somatosensory profiles $\left(\mathrm{X}^{2}=13.53, \mathrm{p}=0.035\right)$ such that a larger proportion of patients in the mechanical hyperalgesia profile were grouped in the adaptive pain cluster. No association was observed between the psychosocial profiles and pain modulatory profiles $\left(\mathrm{X}^{2}=6.65, \mathrm{p}=0.355\right)$. No association between the

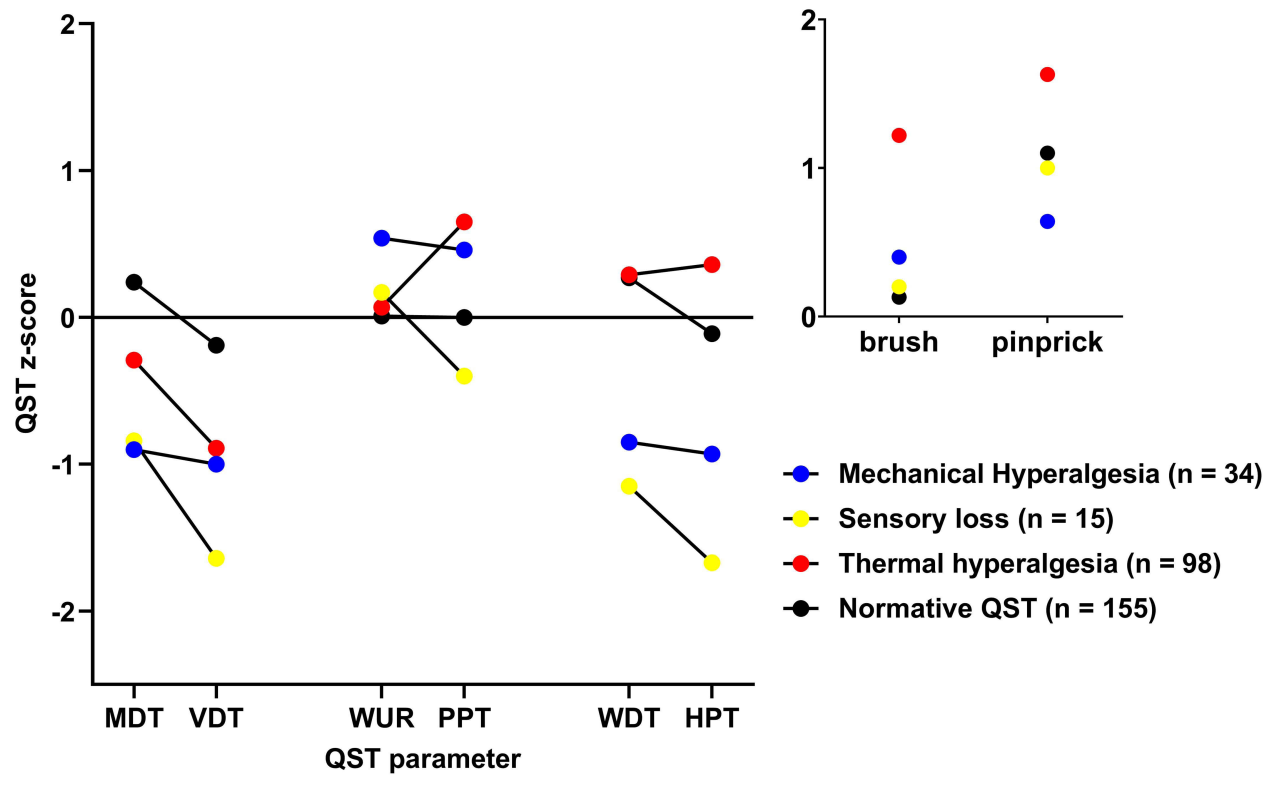

Figure 4 Quantitative sensory testing profiles in adolescents with chronic musculoskeletal pain. Individual patient pain area thresholds were converted into z-scores calculated with reference to within-cohort control measures at the control area. Individual patient control area thresholds were converted into z-scores calculated with reference to between-cohort control measures at the control area. $z$-Scores for dynamic mechanical allodynia to brush and for the presence of painful after-sensations at the end of the 60 -second period after 10 pinprick stimuli were were calculated with reference to the pain intensity reported by the patients using the numerical rating scale (NRS 0-10). An average z-score for all QST parameters for the control and affected area was then calculated for each patient. The z-score plot for each individual patient was grouped according to the closest matching adult mechanism-related profile: mechanical hyperalgesia, sensory loss, thermal hyperalgesia or normative QST. Gain of function (hyperalgesia) is indicated as a positive z-score and a loss of function (sensory loss) as a negative score. Data points $=$ mean.

Abbreviations: MDT, mechanical detection threshold; VDT, vibration detection threshold; WUR, wind-up ratio; PPT, pressure pain threshold; WDT, warm detection threshold; HPT, heat pain threshold; brush, dynamic mechanical allodynia; pinprick, painful after-sensations at the end of the 60 -second period after I and 10 stimuli. 
Dysfunctional central processing $(n=27)$

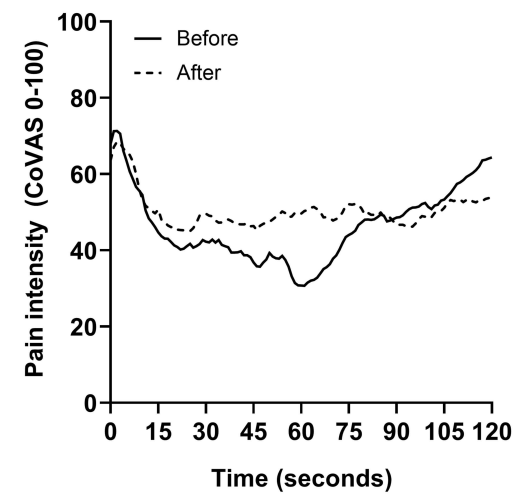

Functional central processing $(n=112)$

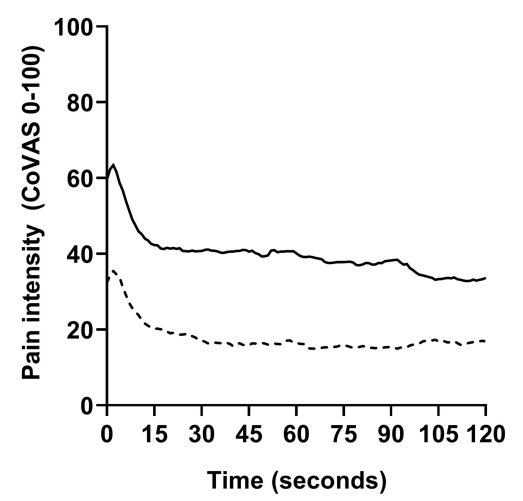

Dysfunctional inhibition $(n=136)$

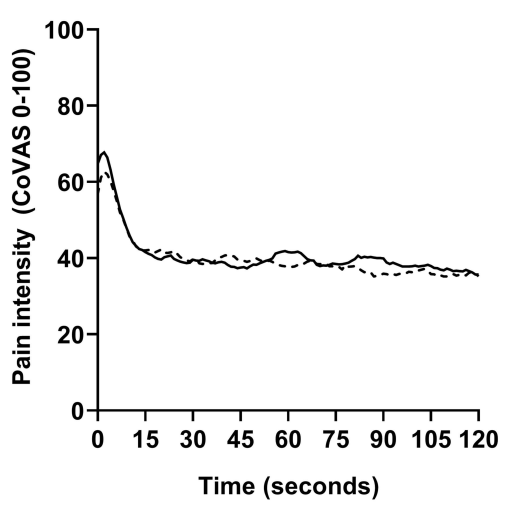

Age-matched controls $=80$

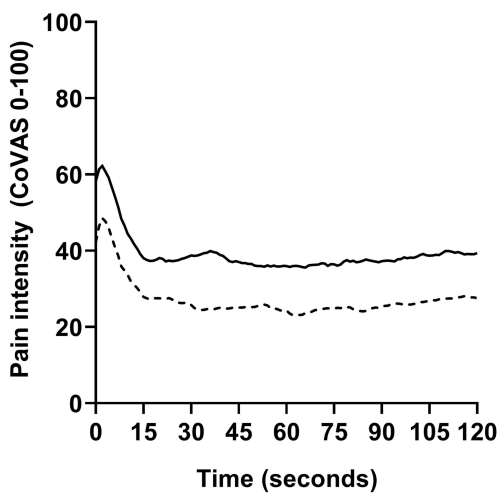

Figure 5 Pain modulation profiles in adolescents with chronic musculoskeletal pain and age-matched controls. Mean pain intensity during the tonic thermal heat stimulations of the conditioned pain modulation assessment. Each individual patient was grouped according to their inhibitory and facilitatory pain modulation responses: dysfunctional central processing (suboptimal or inefficient CPM and presence of temporal summation of pain), dysfunctional inhibition (suboptimal or inefficient CPM and absence of temporal summation of pain), facilitation (optimal CPM and presence of temporal summation of pain) and functional central processing (optimal CPM and absence of temporal summation of pain). A CPM efficiency between $-100 \%$ and $-30 \%$ was considered as optimal, between $-30 \%$ and $-10 \%$ suboptimal and between $-10 \%$ and $+100 \%$ inefficient. Presence of temporal summation of pain was defined as an increase in pain intensity equal or larger than 20/100 (using the CoVAS) during the last 60 seconds of the first test stimulus.

Abbreviation: CoVAS, computerized visual analog scale.

somatosensory profiles and pain modulatory profiles was observed $\left(X^{2}=10.69, p=0.298\right)$. When looking at the individual outcome measures with respect to the distinct profiles, significant differences were observed.

Psychosocial profiles: Adolescent patients grouped in the HSS cluster displayed more dynamic mechanical allodynia than patients grouped in the AP cluster (see Supplementary Table 3). Moreover, more patients in the HSS clusters displayed the presence of painful after-sensations after 10 stimuli in the control and affected area tested than patients in the AP cluster. Patients in the HSS cluster also displayed a significantly higher vibration detection threshold, but lower pressure pain threshold in the affected area, when compared to patients in the AP cluster. Interestingly, patients in the HSS and AP clusters displayed more temporal summation of pain than patients in the HPD cluster.

Somatosensory profiles: Patients allocated to the thermal hyperalgesia profile reported significantly higher scores for the DN4 questionnaire than patients allocated to the normative QST subgroup. Moreover, patients allocated to the thermal hyperalgesia profile were more likely to report their pain neuropathic in nature (see Supplementary Table 4). In addition, patients allocated to the mechanical hyperalgesia profile reported lower scores for the functional disability index than patients allocated in the thermal hyperalgesia profile.

Pain modulatory profiles: Patients allocated in the functional central processing profile reported significantly lower scores for the DN4 questionnaire and were, therefore, less likely to report their pain neuropathic in nature in comparison to patients allocated to the dysfunctional central processing, dysfunctional inhibition or facilitation profiles (see Supplementary Table 5). 


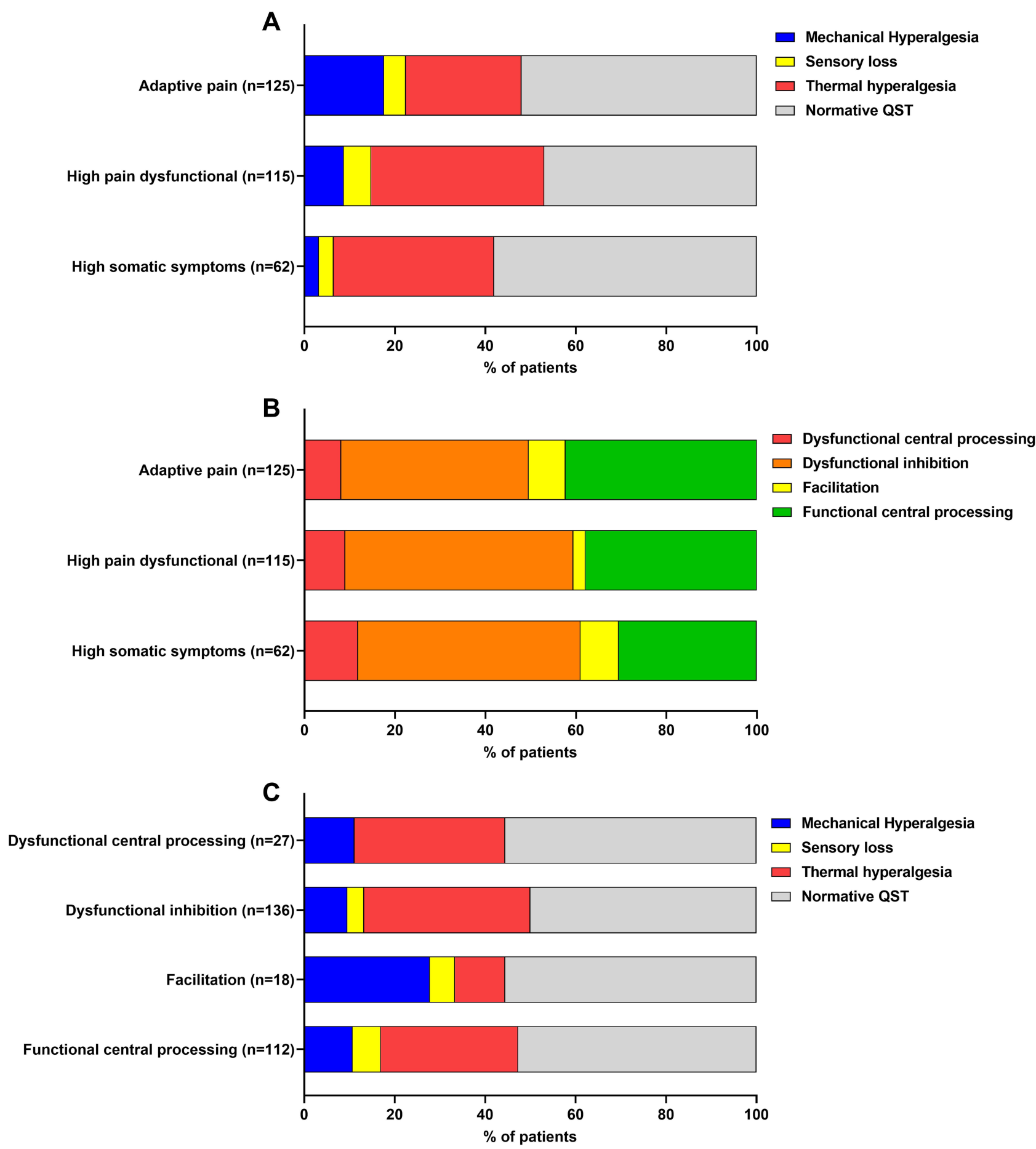

Figure 6 Associations between psychosocial profiles and somatosensory profiles and pain modulatory profiles. (A) The proportion of distinct somatosensory profiles is shown divided by the identified psychosocial profiles. (B) The proportion of distinct pain modulatory profiles is shown divided by the identified psychosocial profiles. (C) The proportion of distinct somatosensory profiles is shown divided by the identified pain modulatory profiles.

\section{Discussion}

Youth with chronic pain are heterogeneous in regard to their clinical presentation. Therefore, the objective of the study was to subgroup pediatric patients with chronic MSK pain that will be phenotypically different from each other based on their psychosocial profile, somatosensory profile and pain modulatory profiles. Overall, patients reported higher pain catastrophizing, more anxiety and depression symptoms, and poor sleep quality than age-matched controls. 
Moreover, patients displayed lower pressure pain thresholds and less efficient conditioned pain modulation than controls. Our analysis revealed that pain assessment through self-reported questionnaires, quantitative sensory testing and conditioned pain modulation identified distinct psychosocial, somatosensory, and pain modulatory profiles (Figure 7).

\section{Psychosocial Phenotyping}

Studies have highlighted differences between the psychosocial characteristics of pediatric patients with chronic pain. ${ }^{12-16,80}$ Similarly to previous cluster analyses on the psychological and behavioural characteristics of pediatric patients with chronic pain, three subgroups were identified, one with high levels of distress and disability, another with relatively low scores of distress and disability, and a third group that scored in between the other two on these measures. ${ }^{12,13,15,80}$ In our study, three distinct profiles were identified based on cluster analysis of self-reported measures of pain catastrophizing, neuropathic pain-like experiences, functional disability, descriptors of pain, anxiety and depression symptoms and sleep quality. The subgroups identified (adaptive pain, high pain dysfunctional, and high somatic symptoms) also differed based on their pain intensity the day of the assessment, and their average, worst and best pain over the last month. This result is important as it highlights the fear-avoidance mechanism ${ }^{81,82}$ that may be at play in the high pain dysfunctional subgroup, but especially the high somatic symptoms subgroup. The high catastrophizing and negative affect of patients in the HPD and HSS psychosocial subgroups may lead them into a cyclical nature of prolonged avoidance of activities that is associated with increased pain, functional impairment and disability. ${ }^{82,83}$ Moreover, our results showed that the high somatic symptom subgroup showed more frequent dynamic mechanical allodynia and presence of painful after-sensations after pinprick stimuli. The high somatic symptom cluster also displayed a higher vibration detection threshold, but lower pressure pain threshold in their most painful location. The associations highlight that the effects of psychosocial factors on QST should not be overlooked, and identifying patients similar to those grouped in the HSS cluster would allow clinicians to intervene early to reduce pain symptoms and its negative impact on the daily lives of the patients.

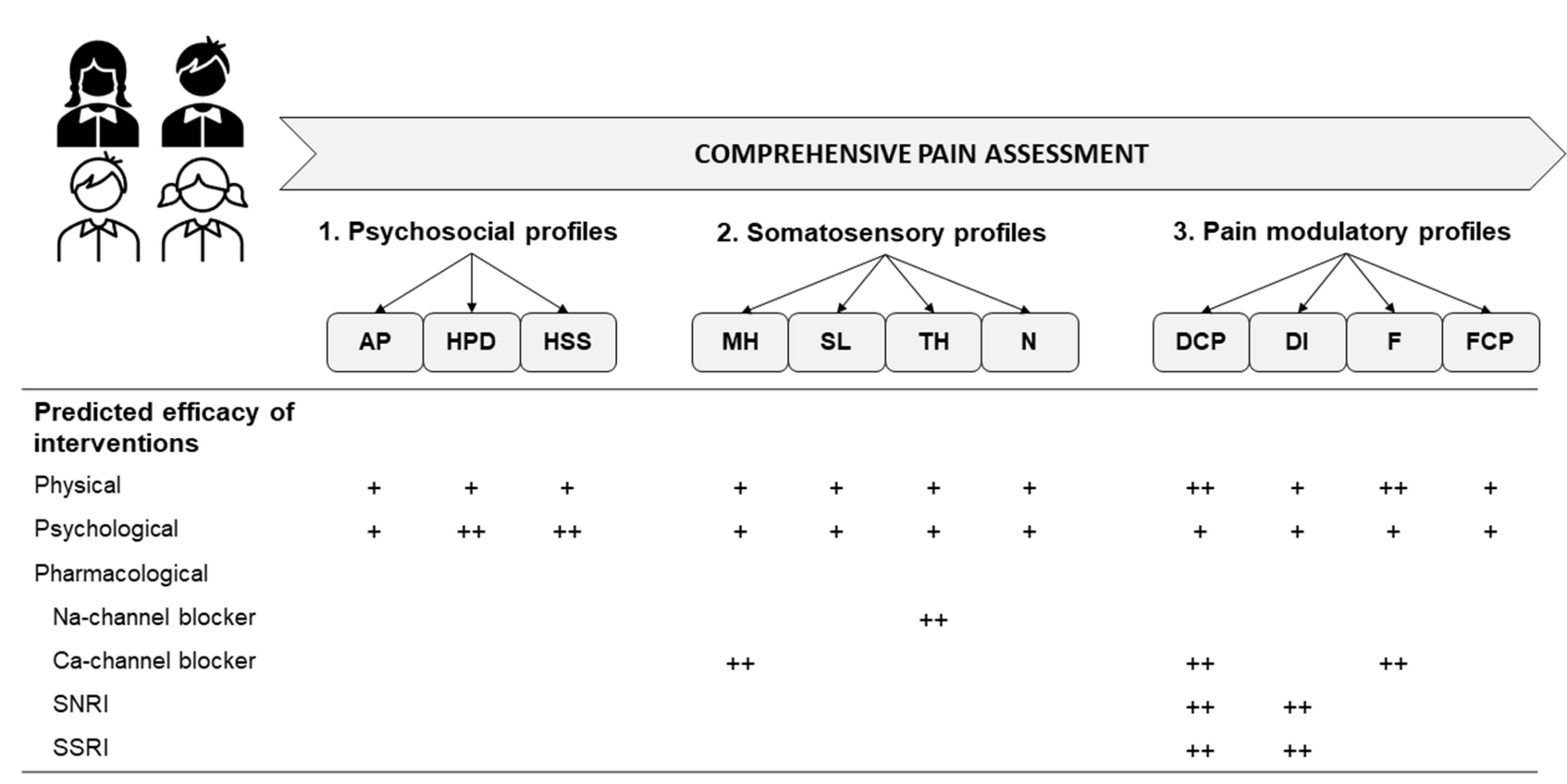

Figure 7 Comprehensive patient pain assessment and rational predicted treatment efficacy. Pain assessment through self-reported questionnaires, quantitative sensory testing and conditioned pain modulation identifies distinct psychosocial, somatosensory, and pain modulatory profiles. Predictions for differential efficacy of treatment approaches across profiles are depicted. + represents beneficial; ++ represents very beneficial.

Abbreviations: AP, adaptive pain; HPD; high pain dysfunctional; HSS; high somatic symptoms; MH, mechanical hyperalgesia profile; SL, sensory loss profile; TH, thermal hyperalgesia profile; N, normative QST profile; DCP, dysfunctional central processing; DI, dysfunctional inhibition; F, facilitation; FCP, functional central processing. 


\section{Somatosensory Phenotyping}

Somatosensory signs vary within diagnostic characteristics of patients with neuropathic pain, and subgrouping based on different profiles may improve mechanism-based treatment. ${ }^{16,84}$ In our sample of adolescents with chronic musculoskeletal pain, we also identified distinct sensory loss, thermal hyperalgesia, and mechanical hyperalgesia profiles, but also included a profile in which patients presented QST values closer to "healthy" controls. Although it is important to consider the sample size of our age-matched controls and methodology that may influence the $z$-scores for some modalities, our results parallel clusters reported in adolescents and adults with neuropathic pain. ${ }^{16,77,78}$ Patients without confirmation of a lesion in the somatosensory system but with altered sensory processing may reflect nociplastic pain as the dominant mechanism at play. ${ }^{85}$

More than half of the patients displayed QST values that were relatively similar to "healthy" controls. Unlike Verriotis et al, whose sample consisted of adolescents with peripheral neuropathic pain, ${ }^{16}$ and our previous work in a sample of pediatric patients and young adults with chronic back pain, ${ }^{86}$ which did not include healthy controls, this study highlights that there are patients that display no gain or loss of sensory functions and, therefore, their pain may be due to other underlying mechanisms.

Sensory loss is common in children with rare conditions (eg, postherpetic neuralgia ${ }^{78}$ ) or with conditions that produce subclinical sensory signs (eg, diabetes ${ }^{87,88}$ ), but was relatively uncommon in our cohort of patients with chronic MSK pain $(5.3 \%)$ similarly to a cohort of patients with peripheral neuropathic pain $(21.2 \%) .{ }^{16}$ This sensory profile is characterized by a loss of small and large fiber function and has been described to be similar to a compression nerve block. ${ }^{78,89,90}$ Therefore, the spontaneous pain, despite the "deafferation" or "painful hypoesthesia", may be likely due to ectopic action potentials generated in proximal sites of injured nociceptors, such as the dorsal root ganglion or the deafferented central nociceptive neurons. ${ }^{91}$

Thermal hyperalgesia was the most common profile in our cohort of patients with chronic MSK pain displayed through increased sensitivity to mechanical and thermal stimuli. Interestingly, a higher proportion of patients in the thermal hyperalgesia profile were more likely to report their pain as neuropathic, highlighting that a change in somatosensory function may be involved in the ongoing pain. Increased thermal sensitivity has been seen in adolescents with complex regional pain syndrome ${ }^{92}$ and chronic musculoskeletal pain $^{93}$; however other studies in youth with functional abdominal pain have observed no difference in heat pain threshold or test temperature when compared to pain-free youth. ${ }^{30,39,94}$ This sensory profile is characterized by relatively preserved large and small fiber sensory functions in combination with heat hyperalgesia, which may be likely due to peripheral sensitization. ${ }^{78,95}$ In response to a painful stimuli, sensitized nociceptors will generate an increased number of action potentials to be processed centrally and interpreted are more intense pain. ${ }^{96,97}$ However, it is important to consider that the thermal stimulation was only conducted in a control area of the body. Sensitized nociceptors in the control area of the body may be associated with an overexpression of pronociceptive mediators, channels and receptors leading to pathological spontaneous discharges and lowered activation threshold for thermal and mechanical stimuli. Therefore, the ongoing pain experienced by the patients may be due to ongoing hyperactivity in surviving nociceptors in the affected area.

Mechanical hyperalgesia was also relatively uncommon in our cohort of patients with chronic MSK pain. This sensory profile was characterized by a loss of heat-sensitive small fiber function in combination with pressure hyperalgesia. Increased sensitivity to pressure has been in observed in a large population of adolescents with chronic pain in comparison to healthy controls, providing evidence of regional sensitization. ${ }^{27}$ However, the dissociation of thermal and mechanical hyperalgesias may be explained by the differences in neural signaling of thermal and mechanical pain that starts with peripheral encoding in distinct subsets of nociceptors or central sensitization, which is more prominent for mechanical stimuli. ${ }^{95,96}$ The increased excitability at the spinal level in response to stimuli may be associated with an increased in the receptive fields of the nociceptive spinal cord neurons. ${ }^{96,97}$ The ongoing pain in this sensory profile may be due to spontaneous activity in the nociceptive system originating from the peripheral and/or central nervous system. 


\section{Pain Modulation Phenotyping}

Improving the diagnostic process by identifying patients with chronic MSK pain based on the results of inhibitory and facilitatory pain modulation responses can provide additional standardized outcomes for clinical trials. ${ }^{98}$ The CPM response is based on a spino-bulbar-spinal loop that involves serotonin and noradrenergic mechanisms in the descending pain inhibitory systems. ${ }^{99,100}$ Impaired CPM has been identified in youth with chronic abdominal, neuropathic and musculoskeletal pain when compared to age-matched controls. ${ }^{10,30,33,38,39,82}$ Facilitated TSP, involving NMDA receptors in humans, ${ }^{101}$ have been shown to be involved in some chronic pain conditions such as sickle cell disease, fibromyalgia, migraines, and functional abdominal pain..$^{15,34-36,40,41}$ Our results provide evidence of distinct combinatory profiles of facilitatory and inhibitory pain modulation responses similarly seen in adults. ${ }^{79}$ Vaegter and Graven Nielsen (2016) observed that adult patients demonstrating impaired CPM and facilitate TSP expressed more pain areas, higher clinical pain intensity and experimental pain sensitivity than patients demonstrating normal CPM and TSP responses. Although this was not observed in our cohort and chronic widespread pain is a chronic conditioned heterogeneous with respect to pain modulation, youth grouped in the dysfunctional central processing may be important to be identified for intervention. With such manifestation of impairment in central pain modulation, these patients are suggested to be at high propensity for widespread pain and comorbidities in the future if not present already. ${ }^{79,102}$

\section{Clinical Implications}

The management and treatment of chronic pain may remain a challenge. Current pain guidelines highlight multidisciplinary management using a biopsychosocial model as the standard of care. A comprehensive use of exercises, physical therapy, cognitive behavioural therapy, and medical treatments with active commitment of the patients and parents are associated with positive clinical outcomes. ${ }^{103,104}$ Studies investigating quantitative sensory testing in relation to musculoskeletal pain have shown the importance of a multidimensional assessment. ${ }^{27,33,105,106}$ Georgopoulos et al highlight that the baseline assessment with quantitative sensory testing was a valuable instrument to predict clinical outcomes including disability in patients with musculoskeletal pain. Improving the diagnostic process by identifying distinct psychosocial, somatosensory and pain modulatory profiles of patients with chronic musculoskeletal pain based on results of quantitative sensory testing, pain-related outcomes, and psychosocial factors may help clinicians provide an improved individualized care to patients. ${ }^{98}$

Exercises, physical therapy and psychological therapies are aimed to focus on helping patients return to their desired level of functioning through progressive engagement in previously avoided activities and a self-management approach to pain. ${ }^{98,103}$ Studies targeting the central pain processes have used physical activity to reduce the presence of temporal summation pain. ${ }^{107,108}$ Therefore, the patients displaying facilitated TSP (ie, grouped in the dysfunctional central processing or facilitation pain modulatory profiles) may benefit from a multidisciplinary program centered on physical activity. ${ }^{109}$

Psychological therapies included in multidisciplinary care, delivered individually or in groups in the pediatric chronic pain population, may break the fear-avoidance cycle, reduce pain symptoms, disability and negative affect, but also modify social environmental factors to enhance functional status. ${ }^{110}$ Hence, a multicomponent approach focused on psychological therapeutic interventions addressing anxiety, depression and poor sleep quality, and on the probable pain hypersensitivity may be more beneficial for patients that are grouped in the high pain dysfunctional and high somatic symptoms cluster who display more functional disability, mental distress and sleep problems.

Multidisciplinary pain management centered on pharmacological treatments and interventional procedures are mainly supported through studies conducted in adults. Several trials in adults with neuropathic pain have used baseline QST phenotyping to identify predictors of treatment response that are relevant to the distinct somatosensory profiles and are supported by different pharmacological profiles. ${ }^{78}$ Clinical trials in adults suggested that sodium channel modulators such as local anesthetics could be useful to treat pain conditions associated with peripheral sensitization, and therefore may be more beneficial for patients grouped in the thermal hyperalgesia somatosensory profile. ${ }^{111,112}$ Moreover, patients with potential involvement of central pain processes (ie, grouped in the mechanical hyperalgesia somatosensory profile) or displaying facilitated TSP (ie, grouped in the dysfunctional central processing or facilitation pain modulatory profiles) 
could benefit more from calcium channel modulators such as gabapentinoids, inhibiting central neuronal sensitization. ${ }^{113}$ Adult patients with a baseline QST profile similar the sensory loss somatosensory profile observed in our cohort displayed a higher efficacy in a retrospective analysis of a placebo-controlled trial with oral opioids. ${ }^{114}$ However, studies have shown very low certainty evidence for the use of opioids for children and adolescents with chronic pain. ${ }^{115}$ Patients with impaired CPM response (i.e. grouped in the dysfunctional central processing or dysfunctional inhibition pain modulatory profiles) could benefit more from selective serotonin reuptake inhibitors or serotonin-noradrenaline re-uptake inhibitors, which augment descending inhibition by spinal monoamine re-uptake inhibition. ${ }^{16,117}$

The overall biopsychosocial approach management and treatment of chronic pain support the clinical relevance of the distinct profiles identified within our cohort. Our predictions for differential efficacy of treatment approaches across profiles are summarized in Figure 7. However, a recent review on the efficacy and safety of pharmacological, physical, and psychological interventions for the management of chronic pain in children observed that although all interventions showed some benefit for reducing pain, most critical outcomes of pain intensity, quality of life, and physical, role and emotional functioning were rated as low or very low certainty. ${ }^{117}$ Moreover, a recent study on children with chronic pain revealed that at their 7-year follow-up, irrespective of whether or not they experienced ongoing chronic pain, they demonstrated worse physical and mental health and continued to seek more frequent health care. ${ }^{118}$ Therefore, the potential efficacy and size effect in treatment response between profiles remains to be proven in future prospective trials.

\section{Limitations}

Data were obtained from a heterogenous sample of patients with diverse pathological diagnoses (eg, scoliosis, osteogenesis imperfecta, chronic widespread pain, etc) that were not considered in this study but is important to consider in pain management. Comparisons between profiles with smaller sample of patients should be interpreted with caution. The QST protocol measures have similarities to the DFNS protocol measures ${ }^{28}$ with modifications or exclusions. Somatosensory profiles were distinct from each other. However, although they are parallel, they do not completely mirror adult mechanism-related profiles. ${ }^{78}$ Somatosensory profiles were based on within- and between-cohort comparisons, and additional pediatric control data will improve the sensitivity of site-, age- and sex-corrected $z$-scores. Only one method assessing the inhibitory and facilitatory pain modulation responses were used. Other studies have used blunt pressure as the test stimulus for the CPM paradigm and have applied a series of heat-pain stimuli of the same temperature to induce temporal summation of pain. ${ }^{15,29}$ Medication taken by the participants were not controlled at the time of the assessment, and medication use was variable. Confirmatory tests and biomarkers may be important to be added to further evaluate adolescents with chronic musculoskeletal pain.

\section{Conclusion}

Our results provide evidence that adolescents with chronic musculoskeletal pain are a heterogeneous population comprising subgroups that may reflect distinct mechanisms and may benefit from different treatment approaches. Screening self-reported questionnaires, QST, and CPM facilitate phenotyping of adolescent with chronic MSK pain in the clinical context. The combination may allow recognition of different subgroups of patients with chronic MSK pain and may ultimately contribute to personalized therapy.

\section{Data Sharing Statement}

The data of this study are available upon request.

\section{Acknowledgments}

This study was financially supported by the Fonds de recherche du Québec-Santé and the Réseau québecois de recherche en douleur. The research analysis was supported by an Edwards PhD Studentship in Pain Research from the Louise and Alan Edwards Foundation awarded to Don Daniel Ocay. The authors would like to thank the participants and all the clinical staff of the Shriners Hospitals for Children, Canada, for their precious collaboration. 


\section{Disclosure}

The research analysis was supported by Edwards PhD Studentship in Pain Research from the Louise and Alan Edwards Foundation awarded to Don Daniel Ocay. The work was supported by the Fonds de recherche du Québec-Santé. The authors declare no conflict of interest.

\section{References}

1. King S, Chambers CT, Huguet A, et al. The epidemiology of chronic pain in children and adolescents revisited: a systematic review. Pain. 2011;152(12):2729-2738. doi:10.1016/j.pain.2011.07.016

2. Goodman JE, McGrath PJ. The epidemiology of pain in children and adolescents: a review. Pain. 1991;46(3):247-264. doi:10.1016/03043959(91)90108-A

3. Schechter NL. Persistent pain in children. In: Bonica's Management of Pain. Lippincott Williams \& Williams; 2009:767-782.

4. Huguet A, Miro J. The severity of chronic pediatric pain: an epidemiological study. J Pain. 2008;9(3):226-236. doi:10.1016/j.jpain.2007.10.015

5. Wojtowicz AA, Banez GA. Adolescents with chronic pain and associated functional disability: a descriptive analysis. $J$ Child Health Care. 2015;19(4):478-484. doi:10.1177/1367493514523157

6. O'Sullivan P, Beales D, Jensen L, Murray K, Myers T. Characteristics of chronic non-specific musculoskeletal pain in children and adolescents attending a rheumatology outpatients clinic: a cross-sectional study. Pediatr Rheumatol Online J. 2011;9(1):3. doi:10.1186/1546-0096-9-3

7. Brattberg G. Do pain problems in young school children persist into early adulthood? A 13-year follow-up. Eur J Pain. 2004;8(3):187-199. doi:10.1016/j.ejpain.2003.08.001

8. Mikkelsson M, El-Metwally A, Kautiainen H, Auvinen A, Macfarlane GJ, Salminen JJ. Onset, prognosis and risk factors for widespread pain in schoolchildren: a prospective 4-year follow-up study. Pain. 2008;138(3):681-687. doi:10.1016/j.pain.2008.06.005

9. Campo JV, Di Lorenzo C, Chiappetta L, et al. Adult outcomes of pediatric recurrent abdominal pain: do they just grow out of it? Pediatrics. 2001;108(1):E1.

10. Holley AL, Wilson AC, Palermo TM. Predictors of the transition from acute to persistent musculoskeletal pain in children and adolescents: a prospective study. Pain. 2017;158(5):794-801. doi:10.1097/j.pain.0000000000000817

11. Eccleston C, Fisher E, Cooper TE, et al. Pharmacological interventions for chronic pain in children: an overview of systematic reviews. Pain. 2019;160(8):1698-1707. doi:10.1097/j.pain.0000000000001609

12. Scharff L, Langan N, Rotter N, et al. Psychological, behavioral, and family characteristics of pediatric patients with chronic pain: a 1-year retrospective study and cluster analysis. Clin J Pain. 2005;21(5):432-438.

13. Schurman JV, Danda CE, Friesen CA, Hyman PE, Simon SD, Cocjin JT. Variations in psychological profile among children with recurrent abdominal pain. J Clin Psychol Med Settings. 2008;15(3):241-251. doi:10.1007/s10880-008-9120-0

14. Wager J, Zernikow B, Darlington A, Vocks S, Hechler T. Identifying subgroups of paediatric chronic pain patients: a cluster-analytic approach. Eur J Pain. 2014;18(9):1352-1362. doi:10.1002/j.1532-2149.2014.497.x

15. Walker LS, Sherman AL, Bruehl S, Garber J, Smith CA. Functional abdominal pain patient subtypes in childhood predict functional gastrointestinal disorders with chronic pain and psychiatric comorbidities in adolescence and adulthood. Pain. 2012;153(9):1798-1806. doi:10.1016/j.pain.2012.03.026

16. Verriotis M, Peters J, Sorger C, Walker SM. Phenotyping peripheral neuropathic pain in male and female adolescents: pain descriptors, somatosensory profiles, conditioned pain modulation, and child-parent reported disability. Pain. 2021;162(6):1732-1748.

17. McGrath PJ, Walco GA, Turk DC, et al. Core outcome domains and measures for pediatric acute and chronic/recurrent pain clinical trials: pedIMMPACT recommendations. J Pain. 2008;9(9):771-783. doi:10.1016/j.jpain.2008.04.007

18. Classification of Chronic Pain. Descriptions of chronic pain syndromes and definitions of pain terms, 2nd Edn. Br J Anaesth. 1995;75(2):254.

19. Edwards RR, Dworkin RH, Turk DC, et al. Patient phenotyping in clinical trials of chronic pain treatments: IMMPACT recommendations. Pain. 2016;157(9):1851-1871.

20. Kosek E, Cohen M, Baron R, et al. Do we need a third mechanistic descriptor for chronic pain states? Pain. 2016;157(7):1382-1386. doi:10.1097/j.pain.0000000000000507

21. Rolke R, Magerl W, Campbell KA, et al. Quantitative sensory testing: a comprehensive protocol for clinical trials. Eur J Pain. 2006;10 (1):77-88. doi:10.1016/j.ejpain.2005.02.003

22. Heimans JJ, Bertelsmann FW, de Beaufort CE, de Beaufort AJ, Faber YA, Bruining GJ. Quantitative sensory examination in diabetic children: assessment of thermal discrimination. Diabet Med. 1987;4(3):251-253. doi:10.1111/j.1464-5491.1987.tb00874.x

23. Thibault A, Forget R, Lambert J. Evaluation of cutaneous and proprioceptive sensation in children: a reliability study. Dev Med Child Neurol. 1994;36(9):796-812. doi:10.1111/j.1469-8749.1994.tb08190.x

24. Hirschfeld G, Zernikow B, Kraemer N, et al. Development of somatosensory perception in children: a longitudinal QST-study. Neuropediatrics. 2012;43(1):10-16. doi:10.1055/s-0032-1307450

25. Meh D, Denislic M. Quantitative assessment of thermal and pain sensitivity. J Neurol Sci. 1994;127(2):164-169. doi:10.1016/0022-510X(94) 90069-8

26. Lautenbacher S, Kunz M, Strate P, Nielsen J, Arendt-Nielsen L. Age effects on pain thresholds, temporal summation and spatial summation of heat and pressure pain. Pain. 2005;115(3):410-418. doi:10.1016/j.pain.2005.03.025

27. Tham SW, Palermo TM, Holley AL, et al. A population-based study of quantitative sensory testing in adolescents with and without chronic pain. Pain. 2016;157(12):2807-2815. doi:10.1097/j.pain.0000000000000716

28. Blankenburg M, Boekens H, Hechler T, et al. Reference values for quantitative sensory testing in children and adolescents: developmental and gender differences of somatosensory perception. Pain. 2010;149(1):76-88. doi:10.1016/j.pain.2010.01.011

29. Hwang PS, Ma ML, Spiegelberg N, Ferland CE. Current methodological approaches in conditioned pain modulation assessment in pediatrics. J Pain Res. 2017;10:2797-2802. doi:10.2147/JPR.S150857 
30. Morris MC, Walker LS, Bruehl S, Stone AL, Mielock AS, Rao U. Impaired conditioned pain modulation in youth with functional abdominal pain. Pain. 2016;157(10):2375-2381. doi:10.1097/j.pain.000000000000660

31. Chretien R, Lavoie S, Chalaye P, et al. Reduced endogenous pain inhibition in adolescent girls with chronic pain. Scand J Pain. 2018;18 (4):711-717. doi:10.1515/sjpain-2018-0071

32. Nahman-Averbuch H, Leon E, Hunter BM, et al. Increased pain sensitivity but normal pain modulation in adolescents with migraine. Pain. 2019;160(5):1019-1028. doi:10.1097/j.pain.0000000000001477

33. Teles AR, Ocay DD, Bin Shebreen A, et al. Evidence of impaired pain modulation in adolescents with idiopathic scoliosis and chronic back pain. Spine J. 2019;19(4):677-686. doi:10.1016/j.spinee.2018.10.009

34. Bettini EA, Moore K, Wang Y, Hinds PS, Finkel JC. Association between pain sensitivity, central sensitization, and functional disability in adolescents with joint hypermobility. J Pediatr Nurs. 2018;42:34-38. doi:10.1016/j.pedn.2018.06.007

35. de Tommaso M, Sciruicchio V, Delussi M, et al. Symptoms of central sensitization and comorbidity for juvenile fibromyalgia in childhood migraine: an observational study in a tertiary headache center. $J$ Headache Pain. 2017;18(1):59. doi:10.1186/s10194-017-0764-8

36. Sherman AL, Morris MC, Bruehl S, Westbrook TD, Walker LS. Heightened temporal summation of pain in patients with functional gastrointestinal disorders and history of trauma. Ann Behav Med. 2015;49(6):785-792. doi:10.1007/s12160-015-9712-5

37. Nir RR, Yarnitsky D. Conditioned pain modulation. Curr Opin Support Palliat Care. 2015;9(2):131-137. doi:10.1097/SPC.0000000000000126

38. Pas R, Rheel E, Van Oosterwijck S, et al. Endogenous pain modulation in children with functional abdominal pain disorders. Pain. 2019;160 (8):1883-1890. doi:10.1097/j.pain.0000000000001566

39. Williams AE, Heitkemper M, Self MM, Czyzewski DI, Shulman RJ. Endogenous inhibition of somatic pain is impaired in girls with irritable bowel syndrome compared with healthy girls. J Pain. 2013;14(9):921-930. doi:10.1016/j.jpain.2013.03.003

40. Brandow AM, Stucky CL, Hillery CA, Hoffmann RG, Panepinto JA. Patients with sickle cell disease have increased sensitivity to cold and heat. Am J Hematol. 2013;88(1):37-43. doi:10.1002/ajh.23341

41. Soee AB, Thomsen LL, Kreiner S, Tornoe B, Skov L. Altered pain perception in children with chronic tension-type headache: is this a sign of central sensitisation? Cephalalgia. 2013;33(7):454-462. doi:10.1177/0333102413476371

42. von Elm E, Altman DG, Egger M, Pocock SJ, Gøtzsche PC, Vandenbroucke JP. The Strengthening the Reporting of Observational Studies in Epidemiology (STROBE) statement: guidelines for reporting observational studies. Epidemiology. 2007;18(6):800-804. doi:10.1097/ EDE.0b013e3181577654

43. Sacks D. Age limits and adolescents. Paediatr Child Health. 2003;8(9):577-578. doi:10.1093/pch/8.9.577

44. Treede R-D, Rief W, Barke A, et al. Chronic pain as a symptom or a disease: the IASP classification of chronic pain for the International Classification of Diseases (ICD-11). PAIN. 2019;160(1):19-27. doi:10.1097/j.pain.0000000000001384

45. Gierthmuhlen J, Enax-Krumova EK, Attal N, et al. Who is healthy? Aspects to consider when including healthy volunteers in QST-based studies-a consensus statement by the EUROPAIN and NEUROPAIN consortia. Pain. 2015;156(11):2203-2211. doi:10.1097/j. pain. 000000000000227

46. David R, Pontone S, Dugué S, et al. Facteurs prédictifs de douleurs neuropathiques postopératoires après chirurgie de scoliose en pédiatrie. Anesth Réanim. 2015;1(Supplement 1):A128-A129. doi:10.1016/j.anrea.2015.07.198

47. Palermo TM. Assessment of chronic pain in children: current status and emerging topics. Pain Res Manag. 2009;14(1):1. doi:10.1155/2009/ 236426

48. Claar RL, Walker LS. Functional assessment of pediatric pain patients: psychometric properties of the functional disability inventory. Pain. 2006;121(1-2):77-84. doi:10.1016/j.pain.2005.12.002

49. Siu YF, Chan S, Wong KM, Wong WS. The comorbidity of chronic pain and sleep disturbances in a community adolescent sample: prevalence and association with sociodemographic and psychosocial factors. Pain Med. 2012;13(10):1292-1303. doi:10.1111/j.1526-4637.2012.01473.x

50. Savedra MC, Holzemer WL, Tesler MD, Wilkie DJ. Assessment of postoperation pain in children and adolescents using the adolescent pediatric pain tool. Nurs Res. 1993;42(1):5-9. doi:10.1097/00006199-199301000-00002

51. Jacob E, Mack AK, Savedra M, Van Cleve L, Wilkie DJ. Adolescent pediatric pain tool for multidimensional measurement of pain in children and adolescents. Pain Manag Nurs. 2014;15(3):694-706. doi:10.1016/j.pmn.2013.03.002

52. Bouhassira D, Attal N, Alchaar H, et al. Comparison of pain syndromes associated with nervous or somatic lesions and development of a new neuropathic pain diagnostic questionnaire (DN4). Pain. 2005;114(1-2):29-36. doi:10.1016/j.pain.2004.12.010

53. de Leeuw TG, der Zanden TV, Ravera S, et al. Diagnosis and treatment of chronic neuropathic and mixed pain in children and adolescents: results of a survey study amongst practitioners. Children. 2020;7(11):208.

54. Mathieson S, Maher CG, Terwee CB, Folly de Campos T, Lin CW. Neuropathic pain screening questionnaires have limited measurement properties. A systematic review. J Clin Epidemiol. 2015;68(8):957-966. doi:10.1016/j.jclinepi.2015.03.010

55. Walker LS, Greene JW. The functional disability inventory: measuring a neglected dimension of child health status. J Pediatr Psychol. 1991;16 (1):39-58. doi:10.1093/jpepsy/16.1.39

56. Crombez G, Bijttebier P, Eccleston C, et al. The child version of the pain catastrophizing scale (PCS-C): a preliminary validation. Pain. 2003;104(3):639-646. doi:10.1016/S0304-3959(03)00121-0

57. Pielech M, Ryan M, Logan D, Kaczynski K, White MT, Simons LE. Pain catastrophizing in children with chronic pain and their parents: proposed clinical reference points and reexamination of the Pain Catastrophizing Scale measure. Pain. 2014;155(11):2360-2367. doi:10.1016/j. pain.2014.08.035

58. Sullivan MJL, Bishop SR, Pivik J. The Pain Catastrophizing Scale: development and validation. Psychol Assess. 1995;7(4):524-532. doi:10.1037/1040-3590.7.4.524

59. Lamé IE, Peters ML, Kessels AG, Van Kleef M, Patijn J. Test-retest stability of the Pain Catastrophizing Scale and the Tampa Scale for Kinesiophobia in chronic pain over a longer period of time. J Health Psychol. 2008;13(6):820-826. doi:10.1177/1359105308093866

60. Chorpita BF, Yim L, Moffitt C, Umemoto LA, Francis SE. Assessment of symptoms of DSM-IV anxiety and depression in children: a revised child anxiety and depression scale. Behav Res Ther. 2000;38(8):835-855. doi:10.1016/S0005-7967(99)00130-8

61. Chorpita BF, Moffitt CE, Gray J. Psychometric properties of the revised child anxiety and depression scale in a clinical sample. Behav Res Ther. 2005;43(3):309-322. doi:10.1016/j.brat.2004.02.004 
62. Buysse DJ, Reynolds CF 3rd, Monk TH, Berman SR, Kupfer DJ. The Pittsburgh Sleep Quality Index: a new instrument for psychiatric practice and research. Psychiatry Res. 1989;28(2):193-213. doi:10.1016/0165-1781(89)90047-4

63. Mollayeva T, Thurairajah P, Burton K, Mollayeva S, Shapiro CM, Colantonio A. The Pittsburgh sleep quality index as a screening tool for sleep dysfunction in clinical and non-clinical samples: a systematic review and meta-analysis. Sleep Med Rev. 2016;25:52-73. doi:10.1016/j. smrv.2015.01.009

64. Raniti MB, Waloszek JM, Schwartz O, Allen NB, Trinder J. Factor structure and psychometric properties of the Pittsburgh Sleep Quality Index in community-based adolescents. Sleep. 2018;41(6). doi:10.1093/sleep/zsy066

65. Larche CL, Plante I, Roy M, Ingelmo PM, Ferland CE. The Pittsburgh Sleep Quality Index: reliability, factor structure, and related clinical factors among children, adolescents, and young adults with chronic pain. Sleep Disord. 2021;2021:5546484. doi:10.1155/2021/5546484

66. Ferland CE, Villemure C, Michon PE, et al. Multi-center assessment of quantitative sensory testing (qst) for the detection of neuropathic-like pain responses using the topical capsaicin model. Can J Pain. 2018;2(1):266-279. doi:10.1080/24740527.2018.1525682

67. Rolke R, Baron R, Maier C, et al. Quantitative sensory testing in the German Research Network on Neuropathic Pain (DFNS): standardized protocol and reference values. Pain. 2006;123(3):231-243. doi:10.1016/j.pain.2006.01.041

68. Potvin S, Stip E, Tempier A, et al. Pain perception in schizophrenia: no changes in diffuse noxious inhibitory controls (DNIC) but a lack of pain sensitization. J Psychiatr Res. 2008;42(12):1010-1016. doi:10.1016/j.jpsychires.2007.11.001

69. Tousignant-Laflamme Y, Page S, Goffaux P, Marchand S. An experimental model to measure excitatory and inhibitory pain mechanisms in humans. Brain Res. 2008;1230:73-79. doi:10.1016/j.brainres.2008.06.120

70. Potvin S, Marchand S. Pain facilitation and pain inhibition during conditioned pain modulation in fibromyalgia and in healthy controls. Pain. 2016;157(8):1704-1710. doi:10.1097/j.pain.0000000000000573

71. Ferland CE, Teles AR, Ingelmo P, Saran N, Marchand S, Ouellet JA. Blood monoamines as potential biomarkers for conditioned pain modulation efficacy: an exploratory study in paediatrics. Eur J Pain. 2018;23(2):327-340.

72. Yarnitsky D, Bouhassira D, Drewes AM, et al. Recommendations on practice of conditioned pain modulation (CPM) testing. Eur J Pain. 2015;19(6):805-806. doi:10.1002/ejp.605

73. Farrar JT, Young JP Jr., LaMoreaux L, Werth JL, Poole RM. Clinical importance of changes in chronic pain intensity measured on an 11-point numerical pain rating scale. Pain. 2001;94(2):149-158. doi:10.1016/S0304-3959(01)00349-9

74. Tsze DS, Hirschfeld G, von Baeyer CL, Suarez LE, Dayan PS. Changes in pain score associated with clinically meaningful outcomes in children with acute pain. Acad Emerg Med. 2019;26(9):1002-1013. doi:10.1111/acem.13683

75. Le S, Josse J, Husson F. FactoMineR: an R package for multivariate analysis. J Stat Softw. 2008;25(1):1-18. doi:10.18637/jss.v025.i01

76. Hair JF. Multivariate Data Analysis: A Global Perspective. Upper Saddle River, N.J.; London: Pearson Education; 2010.

77. Vollert J, Maier C, Attal N, et al. Stratifying patients with peripheral neuropathic pain based on sensory profiles: algorithm and sample size recommendations. Pain. 2017;158(8):1446-1455. doi:10.1097/j.pain.0000000000000935

78. Baron R, Maier C, Attal N, et al. Peripheral neuropathic pain: a mechanism-related organizing principle based on sensory profiles. Pain. 2017;158(2):261-272. doi:10.1097/j.pain.0000000000000753

79. Vaegter HB, Graven-Nielsen T. Pain modulatory phenotypes differentiate subgroups with different clinical and experimental pain sensitivity. Pain. 2016;157(7):1480-1488. doi:10.1097/j.pain.0000000000000543

80. Stone AL, Han GT, Bruehl S, et al. Subgroups of pediatric patients with functional abdominal pain: replication, parental characteristics, and health service use. Clin J Pain. 2020;36(12):897-906. doi:10.1097/AJP.0000000000000882

81. Asmundson GJ, Noel M, Petter M, Parkerson HA. Pediatric fear-avoidance model of chronic pain: foundation, application and future directions. Pain Res Manag. 2012;17(6):397-405. doi:10.1155/2012/908061

82. Vlaeyen JWS, Linton SJ. Fear-avoidance model of chronic musculoskeletal pain: 12 years on. Pain. 2012;153(6):1144-1147. doi:10.1016/j. pain.2011.12.009

83. Vlaeyen JWS, Linton SJ. Fear-avoidance and its consequences in chronic musculoskeletal pain: a state of the art. Pain. 2000;85(3):317-332. doi:10.1016/S0304-3959(99)00242-0

84. Baron R, Forster M, Binder A. Subgrouping of patients with neuropathic pain according to pain-related sensory abnormalities: a first step to a stratified treatment approach. Lancet Neurol. 2012;11(11):999-1005. doi:10.1016/S1474-4422(12)70189-8

85. Kosek E, Clauw D, Nijs J, et al. Chronic nociplastic pain affecting the musculoskeletal system: clinical criteria and grading system. Pain. 2021;162(11):2629-2634. doi:10.1097/j.pain.0000000000002324

86. Ocay DD, Loewen A, Premachandran S, et al. Psychosocial and psychophysical assessment in pediatric patients and young adults with chronic back pain: a cluster analysis. Eur J Pain. 2021.

87. Blankenburg M, Kraemer N, Hirschfeld G, et al. Childhood diabetic neuropathy: functional impairment and non-invasive screening assessment. Diabet Med. 2012;29(11):1425-1432. doi:10.1111/j.1464-5491.2012.03685.x

88. Wilmshurst JM, Ouvrier RA, Ryan MM. Peripheral nerve disease secondary to systemic conditions in children. Ther Adv Neurol Disord. 2019;12:1756286419866367. doi:10.1177/1756286419866367

89. Baumgartner U, Magerl W, Klein T, Hopf HC, Treede RD. Neurogenic hyperalgesia versus painful hypoalgesia: two distinct mechanisms of neuropathic pain. Pain. 2002;96(1-2):141-151. doi:10.1016/S0304-3959(01)00438-9

90. Yarnitsky D, Ochoa JL. Differential effect of compression-ischaemia block on warm sensation and heat-induced pain. Brain. 1991;114(Pt 2):907-913. doi:10.1093/brain/114.2.907

91. Campbell JN, Meyer RA. Mechanisms of neuropathic pain. Neuron. 2006;52(1):77-92.

92. Sethna NF, Meier PM, Zurakowski D, Berde CB. Cutaneous sensory abnormalities in children and adolescents with complex regional pain syndromes. Pain. 2007;131(1-2):153-161. doi:10.1016/j.pain.2006.12.028

93. Lewandowski Holley A, Wilson AC, Cho E, Palermo TM. Clinical phenotyping of youth with new-onset musculoskeletal pain: a controlled cohort study. Clin J Pain. 2017;33(1):28-36. doi:10.1097/AJP.0000000000000371

94. Zohsel K, Hohmeister J, Flor H, Hermann C. Somatic pain sensitivity in children with recurrent abdominal pain. Am J Gastroenterol. $2008 ; 103$ (6):1517-1523. doi:10.1111/j.1572-0241.2008.01911.x

95. Treede RD, Meyer RA, Raja SN, Campbell JN. Peripheral and central mechanisms of cutaneous hyperalgesia. Prog Neurobiol. 1992;38 (4):397-421. 
96. Marchand S. The physiology of pain mechanisms: from the periphery to the brain. Rheum Dis Clin North Am. 2008;34(2):285-309. doi:10.1016/j.rdc.2008.04.003

97. Schaible HG. Emerging concepts of pain therapy based on neuronal mechanisms. Handb Exp Pharmacol. 2015;227:1-14.

98. Vega E, Beaulieu Y, Gauvin R, et al. Chronic non-cancer pain in children: we have a problem, but also solutions. Minerva Anestesiol. 2018;84 (9):1081-1092. doi:10.23736/S0375-9393.18.12367-4

99. Le Bars D, Dickenson AH, Besson JM. Diffuse noxious inhibitory controls (DNIC). II. Lack of effect on non-convergent neurones, supraspinal involvement and theoretical implications. Pain. 1979;6(3):305-327. doi:10.1016/0304-3959(79)90050-2

100. Le Bars D, Dickenson AH, Besson JM. Diffuse noxious inhibitory controls (DNIC). I. Effects on dorsal horn convergent neurones in the rat. Pain. 1979;6(3):283-304. doi:10.1016/0304-3959(79)90049-6

101. Zhou Q, Price DD, Callam CS, Woodruff MA, Verne GN. Effects of the N-methyl-D-aspartate receptor on temporal summation of second pain (wind-up) in irritable bowel syndrome. J Pain. 2011;12(2):297-303. doi:10.1016/j.jpain.2010.09.002

102. Yarnitsky D. Role of endogenous pain modulation in chronic pain mechanisms and treatment. Pain. 2015;156(Suppl 1):S24-31. doi:10.1097/01. j.pain.0000460343.46847.58

103. Simons LE, Sieberg CB, Conroy C, et al. Children with chronic pain: response trajectories after intensive pain rehabilitation treatment. $J$ Pain. 2018;19(2):207-218. doi:10.1016/j.jpain.2017.10.005

104. Randall ET, Smith KR, Conroy C, Smith AM, Sethna N, Logan DE. Back to living: long-term functional status of pediatric patients who completed intensive interdisciplinary pain treatment. Clin J Pain. 2018;34(10):890-899. doi:10.1097/AJP.0000000000000616

105. Georgopoulos V, Akin-Akinyosoye K, Zhang W, McWilliams DF, Hendrick P, Walsh DA. Quantitative sensory testing and predicting outcomes for musculoskeletal pain, disability, and negative affect: a systematic review and meta-analysis. Pain. 2019;160(9):1920.

106. Holbech JV, Bach FW, Finnerup NB, Jensen TS, Sindrup SH. Pain phenotype as a predictor for drug response in painful polyneuropathy-a retrospective analysis of data from controlled clinical trials. Pain. 2016;157(6):1305-1313. doi:10.1097/j. pain.0000000000000563

107. Bishop MD, Beneciuk JM, George SZ. Immediate reduction in temporal sensory summation after thoracic spinal manipulation. Spine J. 2011;11 (5):440-446. doi:10.1016/j.spinee.2011.03.001

108. Pack R, Gilliland R, Mecham A. The treatment of central sensitization in an adolescent using pain neuroscience education and graded exposure to activity: a case report. Physiother Theory Pract. 2018:1-11. doi:10.1080/09593985.2018.1551454

109. Mirek E, Logan D, Boullard K, Hall AM, Staffa SJ, Sethna N. Physical therapy outcome measures for assessment of lower extremity chronic pain-related function in pediatrics. Pediatr Phys Ther. 2019;31(2):200-207. doi:10.1097/PEP.0000000000000587

110. Fisher E, Law E, Dudeney J, Palermo TM, Stewart G, Eccleston C. Psychological therapies for the management of chronic and recurrent pain in children and adolescents. Cochrane Database Syst Rev. 2018;9(9):Cd003968.

111. Demant DT, Lund K, Vollert J, et al. The effect of oxcarbazepine in peripheral neuropathic pain depends on pain phenotype: a randomised, double-blind, placebo-controlled phenotype-stratified study. Pain. 2014;155(11):2263-2273. doi:10.1016/j.pain.2014.08.014

112. Mainka T, Malewicz NM, Baron R, Enax-Krumova EK, Treede RD, Maier C. Presence of hyperalgesia predicts analgesic efficacy of topically applied capsaicin $8 \%$ in patients with peripheral neuropathic pain. Eur J Pain. 2016;20(1):116-129. doi:10.1002/ejp.703

113. Granovsky Y, Yarnitsky D. Personalized pain medicine: the clinical value of psychophysical assessment of pain modulation profile. Rambam Maimonides Med J. 2013;4(4):e0024-e0024. doi:10.5041/RMMJ.10131

114. Edwards RR, Haythornthwaite JA, Tella P, Max MB, Raja S. Basal heat pain thresholds predict opioid analgesia in patients with postherpetic neuralgia. Anesthesiology. 2006;104(6):1243-1248. doi:10.1097/00000542-200606000-00020

115. Cooper TE, Fisher E, Gray AL, et al. Opioids for chronic non-cancer pain in children and adolescents. Cochrane Database Syst Rev. 2017;7(7): Cd012538.

116. Yarnitsky D, Granot M, Nahman-Averbuch H, Khamaisi M, Granovsky Y. Conditioned pain modulation predicts duloxetine efficacy in painful diabetic neuropathy. Pain. 2012;153(6):1193-1198.

117. Fisher E, Villanueva G, Henschke N, et al. Efficacy and safety of pharmacological, physical, and psychological interventions for the management of chronic pain in children: a WHO systematic review and meta-analysis. Pain. 2022;163(1):e1-e19.

118. Wager J, Ruhe AK, Stahlschmidt L, et al. Long-term outcomes of children with severe chronic pain: Comparison of former patients with a community sample. Eur J Pain. 2021;25(6):1329-1341.

Journal of Pain Research

Dovepress

\section{Publish your work in this journal}

The Journal of Pain Research is an international, peer reviewed, open access, online journal that welcomes laboratory and clinical findings in the fields of pain research and the prevention and management of pain. Original research, reviews, symposium reports, hypothesis formation and commentaries are all considered for publication. The manuscript management system is completely online and includes a very quick and fair peer-review system, which is all easy to use. Visit http://www.dovepress.com/testimonials.php to read real quotes from published authors.

Submit your manuscript here: https://www.dovepress.com/journal-of-pain-research-journal 